\title{
Metabolic and body composition effects of newer antiretrovirals in HIV-infected patients
}

\author{
Suman Srinivasa and Steven K Grinspoon \\ Program in Nutritional Metabolism, Massachusetts General Hospital and Harvard Medical School, 55 Fruit Street, \\ LON207, Boston, Massachusetts 02114, USA
}

Correspondence should be addressed to S K Grinspoon Email sgrinspoon@ mgh.harvard.edu

\begin{abstract}
In the absence of a cure, HIV-infected patients are being successfully treated with antiretroviral therapies (ART) and living longer. Indeed, an increasing number of HIV-infected patients are living beyond the age of 50 years, and in that regard, the use of ART has transformed HIV into a chronic medical condition. As more HIV-infected patients are virologically controlled and living longer, the trajectory of disease morbidity has shifted, however, primarily from opportunistic infections and immune dysfunction to metabolic complications. Evidence suggests that HIV-infected patients acquire significant metabolic risks, including lipodystrophic changes, subclinical atherosclerosis, and insulin resistance. The etiology of these metabolic complications specifically in HIV-infected patients is not entirely clear but may be related to a complex interaction between long-term consequences of infection and HIV itself, chronic use of antiretrovirals, and underlying inflammatory processes. Previous classes of ART, such as protease inhibitors (PIs) and reverse transcriptase inhibitors, have been implicated in altering fat redistribution and lipid and glucose homeostasis. Advances in drug development have introduced newer ART with strategies to target novel mechanisms of action and improve patient adherence with multi-class drug combinations. In this review, we will focus on these newer classes of ART, including selected entry inhibitors, integrase inhibitors, and multi-class drug combinations, and two newer Pls, and the potential of these newer agents to cause metabolic complications in HIV-infected patients. Taken together, further reduction of morbidity in HIV-infected patients will require increasing awareness of the deleterious metabolic complications of ART with subsequent management to mitigate these risks.
\end{abstract}

Invited Author's profile

Dr Grinspoon is a Professor of Medicine at the Harvard Medical School, Director of the MGH Program in Nutritional Metabolism and Co-Director of the Nutrition Obesity Research Center at Harvard. He has had a long-standing interest in the metabolic and endocrine complications of HIV disease, with a particular focus on insulin resistance and body composition. He has served on the WHO Technical Advisory Group on Nutrition in HIV Disease and Chaired the AHA State of the Science Conference on Cardiovascular Disease in HIV-infected patients. In addition, he has served as Co-Chair of the Endocrine Society Research Affairs Committee. His work has suggested an increased myocardial infarction rate in HIV-infected patients and highlighted the relative contributions of traditional risk factors, including diabetes and excess visceral fat accumulation, and of non-traditional risk factors, including inflammation and immune activation. He has shown the efficacy of strategies to improve insulin sensitivity and reduce excess visceral fat.

(c) 2014 European Society of Endocrinology Printed in Great Britain
Published by Bioscientifica Ltd. 


\section{Introduction}

An interaction between HIV itself, antiretroviral therapy (ART), and inflammation may exist, such that HIVinfected patients are at higher risk for metabolic complications despite excellent viremic control. However, the contribution of each of these factors individually and in combination with these metabolic complications remains unclear (Fig. 1). Older classes of ART have been previously implicated in worsening metabolic risks, including lipodystrophy, cardiovascular disease, glucose and lipid metabolism, and bone loss $(1,2,3,4,5,6,7,8)$. For example, in a cohort study of over 3800 patients, Brown et al. $(1,2)$ demonstrated that there was an increased prevalence of diabetes mellitus (DM) in HIV (11.5\%) vs non-HIV patients (6.5\%), and more specifically, there was an increased prevalence of DM in HIV-infected patients on ART. Triant et al. (9) demonstrated that HIV-infected patients had a relative risk of 1.75 for acute myocardial infarction (MI) compared with non-infected patients, and furthermore, Worm et al. reported that exposure to particular protease inhibitors (PIs) was associated with an increased relative risk of MI. The relative risk of MI with longer duration of exposure to indinavir or lopinavirritonavir was 1.12 and 1.13 respectively (8). As HIVinfected patients are living longer without a definitive cure, the duration of ART use will continue to lengthen. Medication-induced complications may increase temporally with longer duration of drug use, therefore

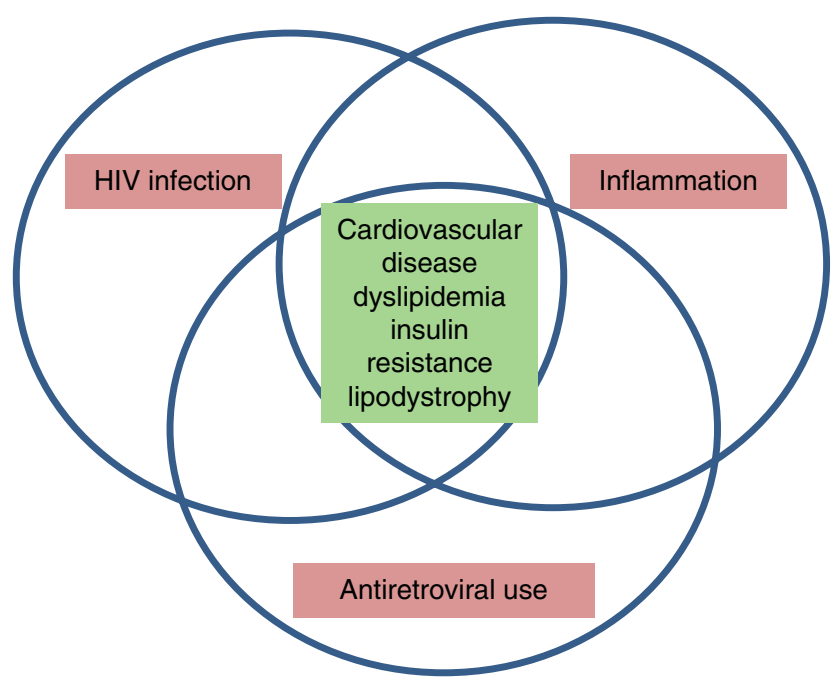

Figure 1

Overlapping contribution of antiretroviral use, HIV infection, and inflammation to metabolic disease. contributing to age-related complications in the older HIV population. This review will focus on potential metabolic consequences of newer classes of ART, including more commonly used entry inhibitors, integrase inhibitors, and multi-class drug combinations, as well as two newer agents in the PI class, atazanavir and darunavir (Table 1). Due to space limitations, effects on bone and vitamin D metabolism will not be included in this review.

\section{Scope of HIV infection and increasing use of ART}

Breakthroughs in understanding the pathophysiological mechanism of HIV infection have led to the development of more efficacious treatment strategies. According to the UNAIDS report on the global AIDS epidemic, the prevalence of people living with HIV globally was estimated to be 35.3 million in 2012. In addition to a $33 \%$ decline in new HIV cases detected since 2001, the number of AIDS-related deaths has also diminished, suggesting that the increased prevalence of HIV may be secondary to improved strategies for ART use effectively decreasing mortality. A total of 10.6 million people were receiving ART as of 2012, and this number has tripled over the last 5 years (http://www.unaids.org/en/ resources/campaigns/GlobalReport2013/globalreport; Date Accessed: November 16, 2013), as increasing efforts are being made to provide these life-saving medications to low- and middle-income countries. It is anticipated by the WHO that the total numbers of deaths prevented could increase from 9 to 12 million between 2013 and 2025 with the use of ART (http://www.who.int/hiv/pub/ progressreports/update2013/en/index.html; Date Accessed: November 16, 2013). The goal of ART use is to inhibit HIV replication to decrease viral burden, thereby increasing CD4 counts and decreasing the risk of opportunistic infections, and to prevent transmission. There are currently six major classes of ART, classified into the mechanism of action by which they interfere with HIV replication (Fig. 2): entry inhibitors, integrase inhibitors, reverse transcriptase inhibitors (RTIs) including nucleoside/nucleotide reverse transcriptase inhibitors (NRTIs) and non-nucleoside reverse transcriptase inhibitors (NNRTIs), PIs, and multi-class drug combinations (http://www.niaid.nih.gov/topics/HIVAIDS/Understanding/Treatment/Pages/arvDrugClasses.aspx; Date Accessed: November 16, 2013). There is ongoing research in drug development for future treatment strategies of HIV 
Table 1 List of trade names and dates of approval in the European Union and United States for selected newer classes of antiretrovirals and protease inhibitors.

\begin{tabular}{|c|c|c|c|c|}
\hline \multirow[b]{2}{*}{ Generic name } & \multicolumn{2}{|c|}{ European Medicines Agency ${ }^{a}$} & \multicolumn{2}{|c|}{ U.S. Food and Drug Administration ${ }^{b}$} \\
\hline & Trade name & Date of approval & Trade name & Date of approval \\
\hline \multicolumn{5}{|l|}{ Entry inhibitor } \\
\hline Maraviroc & Celsentri & September 2007 & Selzentry & August 2007 \\
\hline \multicolumn{5}{|l|}{ Integrase inhibitor } \\
\hline Raltegravir & Isentress & December 2007 & Isentress & October 2007 \\
\hline \multicolumn{5}{|l|}{ Protease inhibitors } \\
\hline Atazanavir & Reyataz & February 2004 & Reyataz & June 2003 \\
\hline Darunavir & Prezista & December 2007 & Prezista & June 2006 \\
\hline \multicolumn{5}{|l|}{ Multi-class drug combinations } \\
\hline Elvitegravir/cobicistat/emtricitabine/tenofovir & Stribild & May 2013 & Stribild & August 2012 \\
\hline Rilpivirine/emtricitabine/tenofovir & Eviplera & November 2011 & Complera & August 2011 \\
\hline Efavirenz/emtricitabine/tenofovir & Atripla & December 2007 & Atripla & July 2006 \\
\hline
\end{tabular}

${ }^{a}$ http://www.ema.europa.eu/ema/; Date Accessed: January 23, 2014

bhttp://www.fda.gov; Date Accessed: January 23, 2014.

infection, and preclinical investigations for other potential targets include: inhibitors of Vif/APOBEC; ESCRT I, II, and III (virus assembly) and TRIM-5 $\alpha$ (virus uncoating) (http://www.niaid.nih.gov/topics/HIVAIDS/ Research/therapeutics/Pages/drug_discovery.aspx; Date Accessed: November 16, 2013). The metabolic effects of newer therapies under development have not yet been assessed.

\section{Potential mechanisms of ART-related metabolic complications}

While the pathogenesis of ART-related metabolic complications is not entirely clear, various hypotheses have been proposed to explain the mechanisms by which older classes of ART may contribute to metabolic abnormalities in HIV-infected patients. NRTIs and PIs have been associated with mitochondrial dysfunction and oxidative stress $(10,11)$, altered adipogenesis and differentiation $(12,13,14)$, impaired glucose transport (15), altered expression of lipid metabolism genes (16), and impaired lipolysis (17).

\section{Requirement for multi-class drug regimens for ART confounds assessment of individual agents, especially in treatment-experienced patients with frequent regimen changes}

Treatment of HIV necessitates multi-class drug therapy in order to counter the viral life cycle at various stages through multiple mechanisms of action. HIV-infected patients can develop resistance or adverse side effects to ART or encounter drug-drug interactions, and with the continual advent of novel ART, changes in medical therapy can be frequent. Combination therapies have now been developed to enhance patient adherence with a less complicated regimen. Although a single pill may be effective for ART in multi-class drug therapy, additive metabolic effects of each individual drug should be considered. While improving viremic control itself may improve metabolic indices (18), inflammation, and even overall cardiovascular disease rates (19), specific adverse

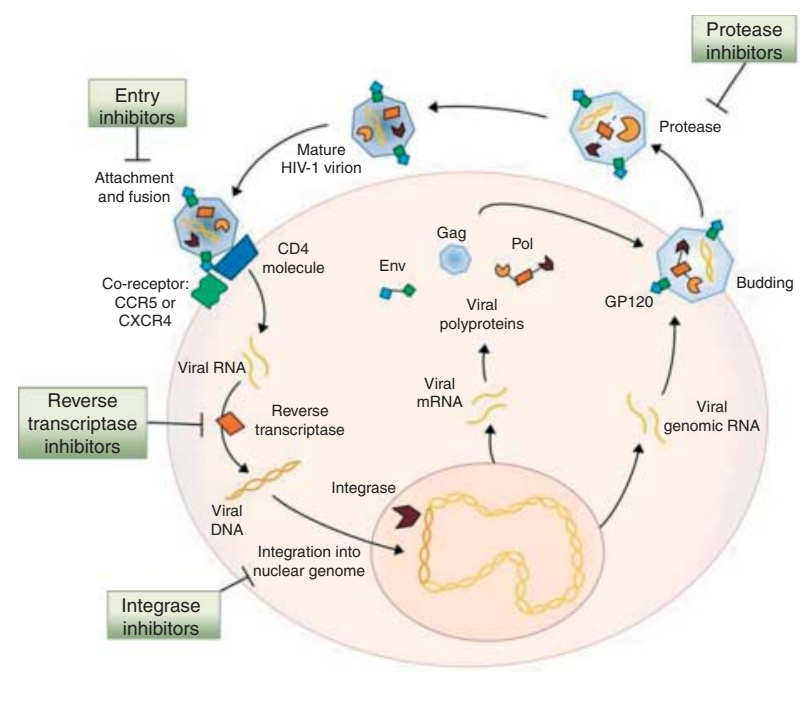

Figure 2

HIV viral life cycle and targets for antiretroviral therapy.

Adapted from Smith et al. (113) with permission from Creative Commons Attribution License. 
effects of individual and combination strategies are important to understand. Moreover, immune activation and related cardiovascular abnormalities, including the presence of high-risk non-calcified coronary plaque, may be present even among HIV-infected patients with good viremic control (20), suggesting the importance of ongoing metabolic monitoring in such patients. In such patients, the choice of ART resulting in optimal viremic control and minimal metabolic consequences is the goal. A major consideration, in this regard, is that the evolving use of multiple newer classes of ART, alone and in combination, can make it difficult to discern which medications are responsible for long-term complications, especially in treatment-experienced HIV-infected patients. Moreover, metabolic complications can occur over time with regard to either initiation or withdrawal of ART. In this review, we will synthesize the literature regarding the development of metabolic effects in previously ART-naïve or treatment-experienced patients and distinguish effects attributable to specific newer agents or combinations of agents in the context of multi-class ART.

\section{Metabolic complications of individual agents in the major classes of ART}

\section{Entry inhibitor}

Maraviroc Maraviroc is a CCR5 receptor antagonist that prevents the interaction between gp120 and CCR5 necessary for macrophage tropic HIV-1 to enter the cell (Fig. 2).

Potential effects on the inflammatory milieu $>$ Preclinical data - The CCR5 receptor plays a role in inflammation through the regulation of monocyte migration (21) and is therefore involved in the process of atherosclerosis. Physiologically, individuals who present with a polymorphism in this receptor, CCR5 $\Delta 32$, not only have increased resistance to developing HIV infection but also are protected from atherosclerotic burden $(22,23)$. Cipriani et al. investigated the effect of maraviroc on reducing atherosclerotic plaque progression and inflammation in dyslipidemic $A p o E^{-/-}$mice exposed to ritonavir, a model of increased atherogenesis and inflammation. The addition of maraviroc in this model attenuated early ritonavir-induced atherosclerotic plaque area by $70 \%$, reduced macrophage infiltration in the aortic wall by $\sim 50 \%$, and decreased expression of chemokines and cytokines, including MCP-1, ICAM-1, and VCAM-1 in aortic tissue (Fig. 3) and IL6 in adipose tissue and
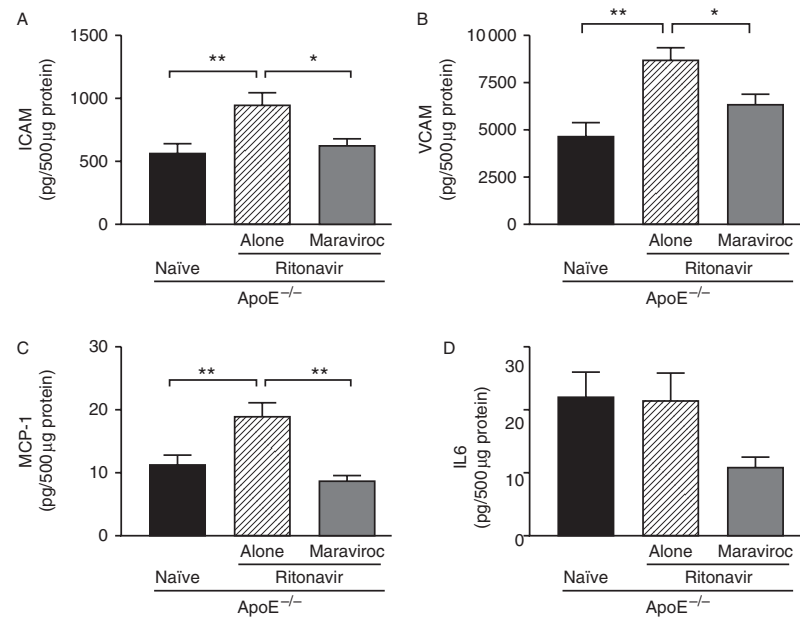

\section{Figure 3}

Effect of maraviroc on plaque inflammation in ritonavirexposed $A p o E^{-1-}$ mice measured by protein levels. (a) ICAM, intercellular adhesion molecule; (b) VCAM, vascular cell adhesion molecule; (c) MCP-1, monocyte chemoattractant protein 1; (d) IL6, interleukin-6. Data are expressed as mean \pm S.E.M. ${ }^{*} * P<0.01, * P<0.05$. Adapted from Cipriani et al. (24) with permission from Lippincott Williams \& Wilkins, Inc.

downregulated CD36 expression on monocytes (24). However, no change in lipid profiles was reported. Another study evaluated maraviroc and its influence on macrophage activation and cardiac dysfunction in $\mathrm{SIV}^{+}$. infected macaques. Results demonstrated that infected macaques treated with maraviroc had preserved diastolic function compared with uninfected control macaques, and in addition, maraviroc treatment lowered myocardial macrophage activation to levels present in uninfected control macaques not receiving treatment, as measured by sCD163 (25). These data, derived from an animal model, suggested that maraviroc may have the potential to reduce atherogenesis in dyslipidemic ART-treated patients.

Human studies $\triangleright$ A number of preliminary studies have been performed to investigate the hypothesis that maraviroc affects inflammatory indices $(26,27,28)$, but more data are clearly needed to definitively assess this effect in HIV-infected patients. In the MERIT trial, treatment-naïve patients with CCR5- tropic HIV were randomized to receive efavirenz or maraviroc both in combination with zidovudine/lamivudine. In this study, patients receiving maraviroc had beneficial effects on fasting lipid profiles. In HIV-infected patients with baseline lipid profiles that were abnormal according to 
National Cholesterol Education Panel (NCEP) guidelines, treatment with maraviroc was associated with significant improvements in total cholesterol and LDL at 96 weeks when compared with treatment with efavirenz (27). Therefore, the effect of maraviroc on lipid parameters, in addition to CCR5 antagonism, may also contribute to favorable effects on atherosclerotic plaque. In a subset of patients from the MERIT trial, Funderburg reported that over 48 weeks, the proportion of treatment-naïve HIV-infected patients with $\mathrm{hsCRP}>2 \mu \mathrm{g} / \mathrm{ml}$ increased in the group of patients treated with efavirenz, while this proportion remained stable in the group of patients treated with maraviroc (28). Hsue et al. evaluated the effect of maraviroc on vascular function using flow-mediated vasodilation (FMD). When treatment-experienced HIVinfected men were randomized to receive either placebo or maraviroc for 24 weeks in addition to their current regimen, HIV-infected men treated with maraviroc tended to have an increase in FMD from baseline, but this difference did not reach statistical significance (29). Taken together, these data on animal and human studies suggest that maraviroc may have favorable effects on cardiovascular burden, but further evaluation of the mechanism of this effect and assessment with respect to reduction or prevention of cardiac events in human trials is necessary.

Effects on glucose homeostasis $\bullet$ Bigoloni et al. investigated glucose homeostasis parameters in ART-experienced HIV-infected patients who were placed on two different NRTI sparing regimens including raltegravir and etravirine with either maraviroc or darunavir/ritonavir. The study reported that more HIV-infected patients were newly diagnosed with DM in the maraviroc group; however, these results were not statistically significant in comparison with the group treated with darunavir/ritonavir at 156 weeks. By contrast, those treated with the maraviroc combination demonstrated a statistically significant increase in BMI and waist circumference. Both treatment groups also had a significant decrease in HOMA$\beta \%$ (30). More studies are needed to address maraviroc's effects on glucose homeostasis.

\section{Integrase inhibitors}

Raltegravir $\bullet$ Raltegravir targets the HIV enzyme integrase, which prevents integration of viral DNA into the host chromosome (Fig. 2). Initial studies suggested that raltegravir can be used for intensification of ART treatment by reducing viral load further than combinations of other antiretrovirals (31); however, these data are inconsistent $(32,33)$. Raltegravir has been used to treat HIV-infected patients successfully without necessity for boosting with ritonavir, which affords the opportunity for patients to avoid known adverse side effects of PIs.

Effects on lipid parameters $>$ Severe dyslipidemia with triglycerides $>5000 \mathrm{mg} / \mathrm{dl}$ was reported in a patient who presented with lipemia retinalis 7 months after commencement of raltegravir and emtricitabine in addition to a prior regimen of lopinavir/ritonavir and tenofovir, and the hypertriglyceridemia normalized rapidly in 2 weeks with discontinuation of the lopinavir/ritonavir and addition of fenofibrate and omega-3 fatty acids (34). A drug-drug interaction between raltegravir and lopinavir-ritonavir was cited as the etiology for the hypertriglyceridemia; however, no clear mechanism exists, as these antiretrovirals do not mutually interact via cytochrome P450. In addition, the contribution of emtricitabine to dyslipidemia is uncertain. In the SPIRAL study enrolling ART-experienced patients, there was a reduction in triglycerides, LDL, and total cholesterol from baseline starting at 4 weeks, which persisted through 48 weeks in the raltegravir group vs the ritonavir-boosted PI group (35) (Fig. 4). Fewer patients in the raltegravir group were on

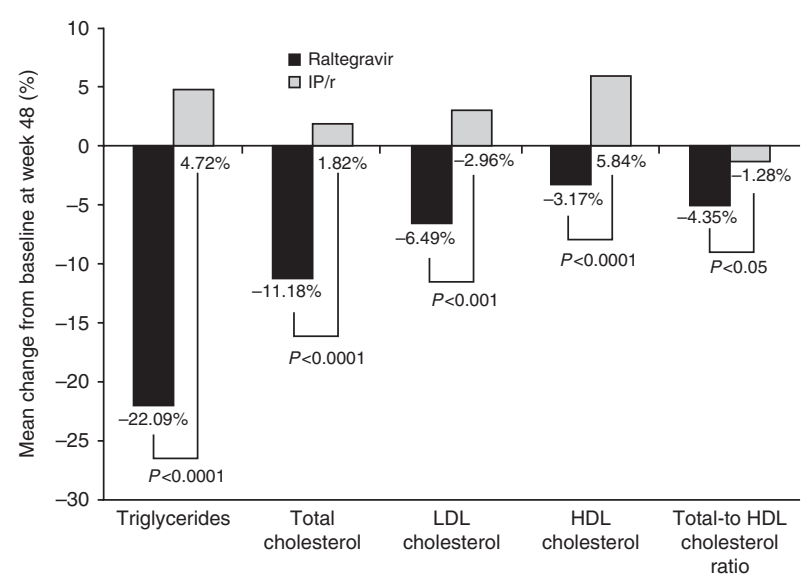

\section{Figure 4}

Changes in fasting lipid parameters from baseline to 48 weeks in the SPIRAL study investigating the substitution of raltegravir for ritonavir-boosted protease inhibitors (PIs) in HIV-infected patients. Data are represented as percentage change in concentration from baseline to week 48. IP/r, ritonavir-boosted PI. Adapted from Martinez et al. (35) with permission from Lippincott Williams \& Wilkins, Inc. 
lipid-lowering therapy compared with the ritonavirboosted PI group. The relationship in the improvement in lipid parameters and body composition was not fully investigated. Switching to raltegravir from a ritonavirboosted PI regimen also had a significant effect on other LDL properties in the SPIRAL substudy. After 48 weeks of raltegravir use, there was a significant increase in LDL particle size and a significant decrease in cholesterol content of small and dense LDL subfractions and lipoprotein-associated phospholipase A2 and PCSK9 plasma concentrations, but this did not differ from the group that remained on a ritonavir-boosted PI regimen. By contrast, there was a significant decrease in total cholesterol, LDL, non-HDL, ApoB, and Lp(a) in the raltegravirtreated group compared with the group remaining on a ritonavir-boosted PI regimen, which suggested a more favorable antiatherogenic phenotype in the raltegravir group (36). The SECOND LINE study investigated treatment-experienced HIV-infected patients who failed firstline therapy and were then randomized to receive ritonavir-boosted lopinavir plus two or three NRTIs or raltegravir. After 48 weeks on the new regimen, total cholesterol, LDL, and HDL increased significantly in the raltegravir group, while there was no significant change in triglycerides (37). The SWITCHMRK trial demonstrated marked reduction in total cholesterol, non-HDL cholesterol, and triglycerides at 12 weeks in ART-experienced patients that were switched from a regimen that included lopinavir/ritonavir to raltegravir. Changes in LDL and HDL did not significantly differ between the groups at 12 weeks (38)

Several studies also investigated the use of raltegravir in ART-naïve patients. The STARTMRK study investigated treatment naïve HIV-infected patient with raltegravir vs efavirenz in combination with tenofovir/emtricitabine. Despite a lower prevalence of lipid-lowering therapy in the raltegravir-treated patients, total cholesterol, HDL, and LDL increased less at 48, 96, 144, and 240 weeks in the raltegravir-treated patients compared with the efavirenztreated group. With respect to the effects on triglyceride levels, triglycerides demonstrated a small decrease at 48 and 96 weeks in the raltegravir-treated group but increased by the end of the trial. However, this increase was less than that seen in the efavirenz-treated group $(39,40,41,42)$. Eron et al. studied the dose-related effects in a trial using once- or twice-daily raltegravir in combination with tenofovir and emtricitabine in treatment-naïve patients. Twice-daily raltegravir improved virological response; however, there was no consistent pattern in changes in lipid parameters between once- and twice-daily administration (43). Raltegravir was compared with efavirenz in combination with both tenofovir and lamivudine in ART-naïve patients. The changes in LDL and triglyceride levels from baseline at 240 weeks were not significantly different between groups, and the elevation in total cholesterol and HDL was smaller in the raltegravir group compared with the efavirenz group (44). Treatmentnaïve patients were started on raltegravir in combination with abacavir/lamivudine in the SHIELD study. While there was an increase at 48 weeks in fasting total cholesterol, HDL, and LDL, the total cholesterol and LDL remained at levels below NCEP guidelines, and the triglyceride levels were stable on the raltegravir and abacavir/lamivudine combination. Lipid particle size was investigated using nuclear magnetic resonance. After 48 weeks, there was a significant increase in percent change from baseline in total LDL particle concentration, and total, large, and medium HDL particle concentrations, but no change was detected in small HDL particle concentration, LDL size, or small LDL particle concentration (45). More studies are needed to investigate the independent effects of raltegravir on lipid parameters, not confounded by the simultaneous use of PIs.

Effects on endothelial function - Endothelial dysfunction was measured by brachial FMD and microvascular function was measured by hyperemic velocity in treatment-experienced HIV-infected patients treated with raltegravir in a randomized, double-blinded, placebocontrolled trial. At 24 weeks, the average rates of change of FMD and hyperemic velocity did not differ between raltegravir- and placebo-treated groups (46). A subanalysis was performed between immunologic responders and non-immunologic responders, which similarly did not show any significant difference between those treated with raltegravir or placebo. In a substudy of the SPIRAL study, FMD and lipid profiles were evaluated in HIV-infected patients either continuing a ritonavir-boosted PI regimen or switching to raltegravir. FMD results did not differ within or between groups at 24 and 48 weeks when compared with baseline, and similarly no changes in FMD were seen between the groups after excluding patients on lipid-lowering therapy. Those patients treated with raltegravir had significant decreases in total cholesterol, LDL, non-HDL, and triglycerides from baseline after 32 weeks of therapy; however, the raltegravir group tended to have better lipid profiles at baseline. Only triglyceride levels were significantly lower in the raltegravir group at 32 weeks when compared with the PI-treated group. The beneficial effect on lipid profiles did not translate into 
improved FMD in the raltegravir-treated patients (47). Over a short treatment course, use of raltegravir has similar effects on endothelial function compared with other ART.

Effects on inflammatory indices - The ANRS 138 EASIER study was a 48-week randomized trial investigating treatment-experienced HIV-infected patients with virologic suppression who were switched from an enfuvirtidebased ART regimen to a raltegravir-based ART regimen. At 24 weeks, levels of biomarkers of inflammation, including IL6, hsCRP, and D-dimer, were significantly decreased from baseline in the raltegravir-based ART regimen by $30 \%, 46 \%$, and $40 \%$ respectively (48). There was no further decrease at 48 weeks. As there was no change in the proportion of virologically suppressed patients over the course of the study, this mechanism was unlikely to explain differences in inflammatory markers between the groups. It remains uncertain whether the decrease in inflammatory markers seen in the ANRS 138 EASIER study was secondary to the addition of raltegravir or the withdrawal of enfuvirtide. Further decreases in inflammatory markers, including hsCRP, MCP-1, OPG, IL6, $\mathrm{TNF} \alpha$, and D-dimer, and insulin were seen after 48 weeks in the treatment-experienced group switched to raltegravir vs those continuing a ritonavir-boosted PI regimen (49), while no significant change was seen in IL10, ICAM-1, VCAM-1, E- and P-selectin, and adiponectin. Markers of endothelial function were less affected, consistent with the lack of effect on FMD in previous studies $(46,47)$. Lake et al. investigated monocyte activation markers in ARTexperienced HIV-infected women with increased central adiposity on a NRTI regimen who were asked to continue the same PI or NNRTI or switch to raltegravir. There was a significant reduction in sCD14 levels at 24 weeks, but no change was measured in SCD163 or I-FABP levels in those switched to raltegravir (50).

Data are also available from ART-naïve treatment studies. Two groups of treatment-naïve HIV-infected patients started on darunavir/ritonavir plus raltegravir were evaluated for changes in inflammatory biomarkers in association with presence or absence of virologic response at 48 weeks. Those patients with baseline viral load $>100000$ copies/ml demonstrated increased CD4 and CD8 activation and IL6, IP-10, sCD14, and D-dimer levels at baseline. Markers of inflammation and microbial translocation, IP-10, sCD14, and D-dimer, were attenuated in both groups to similar absolute levels, despite the fact that those in the virologic failure group demonstrated higher baseline levels of inflammatory indices. So, while the absolute levels were not significantly different at
48 weeks, the reduction in IP-10, sCD14, and D-dimer levels at 48 weeks from baseline was significantly more in those with virologic failure compared with those without virologic failure. Baseline T-cell activation and increased inflammatory markers were not predictors of virologic failure (51). In another study of treatment-naïve patients with viral load $>5000$ copies $/ \mathrm{ml}$ who were started on raltegravir in combination with lopinavir/ritonavir or emtricitabine/tenofovir, LPS and sCD14 levels were compared with non-HIV-infected controls. Baseline levels of LPS and sCD14 were increased in the HIV-infected patients and inversely correlated with CD4 counts; however, there was a decrease in LPS after 4 weeks of treatment concurrent with an increase in CD4 counts and a decrease in sCD14 after 24 weeks of treatment. By 48 weeks, the sCD14 level had normalized, but the LPS level remained elevated compared with healthy controls (52). Concurrent with these changes in LPS and sCD14, there was a decrease in immune activation of T cells, suggesting that microbial translocation may be implicated in immune activation and disease progression. Taken together, these data on treatment-experienced and naïve patients are unclear as to whether the initiations of raltegravir or withdrawal of other drugs may reduce inflammation and insulin resistance in HIV-infected patients.

Effects on body composition - While older classes of ART, more classically PIs and NRTIs, have been implicated in lipodystrophic changes in HIV-infected patients, one case report suggests the new onset development of a buffalo hump in treatment-experienced HIV-infected patient 3 months after initiating treatment with raltegravir and atazanavir, which worsened over the course of 6 months (53). However, the contribution of raltegravir to body fat changes in this case was unclear, as atazanavir, a PI, itself may contribute to lipodystrophy in HIVinfected patients (54) and prior use of other PIs and NRTIs may have also contributed. Treatment-experienced HIV-infected women treated with an NRTI regimen were followed for body composition changes after having switched their PI or NNRTI regimen to raltegravir. Visceral adipose tissue assessed by CT scan decreased in the group treated with raltegravir by $3.6 \%$, while the group with no change in their ART had an increase of $1.9 \%$ (55); this change was not statistically significant at 24 weeks. Body composition was also evaluated in the STARTMRK study involving ART-naïve patients receiving either raltegravir or efavirenz in combination with tenofovir and emtricitabine. Overall, BMI increased in both groups, and at 156 weeks, there was an increase in fat in the trunk 
and limbs of $19 \%$ in the raltegravir group and $31 \%$ in the efavirenz group (41), similar to results at 48 and 96 weeks (40). At 156 weeks, lipoatrophy was notable in $4 \%$ of the raltegravir group vs $6 \%$ of the efavirenz group, but the total number of patients studied was small (40). Previous use of ART may complicate assessment of whether lipodystrophic changes are associated with raltegravir.

\section{Protease inhibitors}

Atazanavir $>$ Atazanavir inhibits the viral Gag and GagPol polyproteins in the HIV-1-infected cells, which prevent formation of mature virions (Fig. 2). Atazanavir is administered once daily with or without ritonavir boosting.

Effects on lipid parameters - In the SABAR study, HIVinfected patients on stable ART for at least 3 months were randomized to either continue on their current PI regimen in combination with the same nucleoside backbone or substitute their previous PI regimen for atazanavir. Approximately $30 \%$ of these patients in both groups were already on lipid-lowering therapies. Fasting lipids were checked at 24 weeks, and the atazanavir group had a significant decrease in total, LDL, VLDL, and non-HDL cholesterol, triglycerides, and LDL particles, and in addition, the total and non-HDL cholesterol and triglycerides also significantly decreased when compared with the control group (56). These patients were also assessed for endothelial function; however, there was no notable change in the atazanavir group in FMD, despite improvement in the lipid parameters. HIV-infected patients with prior virologic failure on their ART were switched to either atazanavir or lopinavir/ritonavir with two NRTIs. At 48 weeks, there was a significant decrease in total cholesterol, LDL, and triglycerides in the atazanavir group, despite a significantly greater reduction in viral load in the lopinavir/ritonavir group. There was an increase in the proportion of patients in the atazanavir group who achieved optimal LDL and total cholesterol levels at 48 weeks by NCEP-ATP II guidelines, while there was a decrease in the proportion of patients in the lopinavir/ritonavir group who achieved these optimal levels (57). HIV-infected patients with prior history of hyperlipidemia and PI use with a thymidine analogue were switched to atazanavir/ritonavir in combination with either abacavir/lamivudine or tenofovir/emtricitabine. At 48 weeks to 1 year, there was a significant decrease in total cholesterol, LDL, and triglyceride in both groups, but the change was not statistically significant between groups (58). Treatment-experienced HIV-infected patients with a known history of hyperlipidemia were switched to atazanavir with or without ritonavir in addition to two to three NRTIs. After 24 weeks, there was a significant reduction in total cholesterol and triglycerides by 18 and $46 \%$ respectively, but by 48 weeks, the triglycerides increased again, but still remained below baseline levels. The increase in triglycerides may have been associated with an increase in the number of patients receiving ritonavir boosting at week 24 . No significant changes in LDL or HDL were noted (59). Lipid parameters were compared between ART-experienced HIV-infected patients who were on a ritonavir-boosted PI regimen with two NRTI that had their PI regimen immediately switched to ritonavir-boosted atazanavir or had a 24-week delayed switch. Those who were immediately switched to atazanavir/ritonavir had a more significant reduction in total cholesterol, LDL, non-HDL cholesterol, triglycerides, apolipoprotein B, and $\operatorname{Lp}(\mathrm{a})$. Those who had a delayed switch had similar improvements in their lipids at 48 weeks compared with those who had been immediately switched (60). The ATAZIP study also showed a significant decrease in triglycerides and cholesterol at 48 weeks in HIV-infected patients who were switched from lopinavir/ ritonavir to atazanavir/ritonavir with the same NRTI backbone compared with those who remained on lopinavir/ritonavir. There were no differences observed for LDL or HDL (61). Similarly, HIV-infected patients previously on a stable PI regimen were switched to atazanavir boosted or unboosted or continued on their current PI regimen in the SWAN study. At 48 weeks, there was a significant reduction in total cholesterol, non-HDL cholesterol, and triglycerides in the atazanavir group (62). HIV-infected patients who were initiated on atazanavir regardless of whether other ART in their regimen had been discontinued had decreased total cholesterol and triglycerides at 24 weeks. The use of ritonavir-boosted atazanavir, baseline total cholesterol levels, as well as discontinuation of an NNRTI or PI from a previous regimen were significant and independent predictors for the change in total cholesterol in the atazanavir-treated group, whereas prior lipodystrophy was not a significant predictor (63). Switching a PI regimen to atazanavir may be associated with improved lipid profiles in treatment-experienced patients. The effects of such changes on CVD risk are unknown, but in the D:A:D cohort, the incidence of MI was higher in ARTexperienced HIV-infected patients with no exposure to atazanavir vs those with $>3$ years of atazanavir use, and there was no overall significant independent association 
of exposure of atazanavir to MI risk (64). Lipid profiles were also evaluated in treatment-naive patients initiated on atazanavir. In the ACTION study, ART naïve HIVinfected patients were initiated on abacavir/lamivudine/ zidovudine or atazanavir with lamivudine/zidovudine, and at 48 weeks, there were minimal changes in lipid and glucose parameters (65). Vrouenraets et al. compared treatment-naïve HIV-infected patients receiving either atazanavir/ritonavir or saquinavir/ritonavir in combination with tenofovir/emtricitabine in the BASIC study. Overall, total and HDL cholesterol and ApoA1 increased significantly in both the atazanavir/ritonavirand saquinavir/ritonavir-treated groups at 48 weeks from baseline; however, between groups, only HDL was significantly higher in the saquinavir/ritonavir-treated group (66). Lipid parameters and cardiovascular risk were evaluated in ART-naïve HIV-infected patients initiating a ritonavir-boosted PI regimen with atazanavir, fosamprenavir, or saquinavir. At 6 months, the atazanavir group had a significant decrease in total cholesterol, despite having a higher baseline total cholesterol level, while other groups treated with fosamprenavir or saquinavir had a rise in total cholesterol. Similarly, the atazanavir group started with a higher HeartScore, which predicts cardiovascular risk, but this score tended to decrease in the atazanavir group and tended to increase in the other two treatment groups (67). Treatment-naïve patients in the CASTLE study received either atazanavir/ritonavir or lopinavir/ritonavir in combination with tenofovir/ emtricitabine, and after 48 weeks, the atazanavir group had significantly lower mean percentage changes in total cholesterol, non-HDL cholesterol, and triglycerides (68). To investigate the effects of a ritonavir sparing regimen, the SPARTAN study compared use of atazanavir and raltegravir vs atazanavir/ritonavir and tenofovir/ emtricitabine in treatment-naïve HIV-infected patients. By 24 weeks, the triglycerides, total, and non-HDL cholesterol tended to increase more in the atazanavir/ ritonavir and tenofovir/emtricitabine group (69). Treatment-naïve HIV-infected patients were randomized to receive nevirapine or atazanavir/ritonavir both with tenofovir/emtricitabine in the ARTEN study. The nevirapine group had a significant increase in total cholesterol, HDL, LDL, and ApoA1 from baseline to 48 weeks when compared with the atazanavir group, while the atazanavir group had a greater increase in triglycerides; however, the Framingham risk score remained similar between both groups (70). Ritonavir boosting may confound the effects of atazanavir on lipid parameters in treatment-naïve HIV-infected patients.
Effects on inflammatory indices $>$ Hileman et al. (71) posited that atazanavir may have increased antiinflammatory properties secondary to known side effects of hyperbilirubinemia based on atazanavir's mechanism of action (72). In a retrospective study of HIV-infected patients on stable ART for at least 12 weeks, total bilirubin levels were significantly higher in patients on atazanavir; however, this was not associated with FMD or inflammatory or oxidation markers, including IL6, hsCRP, D-dimer, sTNFR-1 and II, sICAM-1, and sVCAM-1, with the exception of increased fibrinogen (71). Similarly, in a study by Flammer et al. (73), there was no significant difference in FMD or inflammatory or oxidative stress markers at 24 weeks in treatment-experienced patients on two NRTIs and a PI that were switched to atazanavir vs those who remained on their PI regimen, although lipid parameters improved significantly more in the atazanavir group. Colafigli et al. also demonstrated that HIV-infected patients who were switched to an atazanavir-containing regimen had significant improvements in lipid parameters, but no significant change in cardiovascular risk score as assessed by the CUORE project risk calculator, which has been validated in the Italian population. When normalized for age, however, there was a significant reduction in the CUORE score (74). In the ARIES trial, treatment-naïve HIV-infected patients were randomized to receive abacavir/ lamivudine/atazanavir with or without ritonavir. At 144 weeks, there was no significant change from baseline in IL6 or hsCRP in either group, but there was a significant reduction in Lp-PLA2 in both groups (75). In the AVATAR study, cIMT was compared between those ART-experienced HIV-infected patients exposed to atazanavir/ritonavir and those who were not. At 12 and 18 months, cIMT decreased significantly in the atazanavir/ritonavir group compared with those not exposed to atazanavir, who demonstrated an increase in cIMT (76). More long-term studies may demonstrate anti-inflammatory properties of atazanavir with longer duration of exposure.

Effects on glucose homeostasis - Insulin sensitivity, measured by hyperinsulinemic euglycemic clamp, and triglyceride levels significantly improved in a group of ART-experienced HIV-infected patients who switched their baseline PI regimen to atazanavir/ritonavir for 12 weeks, even though $67 \%$ of patients were already on ritonavir, and there were no changes in body composition (77). Guffanti et al. (78) studied treatment-experienced HIV-infected patients with known insulin resistance whose PI-based regimen was switched to an unboosted atazanavir regimen, and they report that glucose tolerance as measured by the 
2-h postprandial glucose during oral glucose tolerance testing was significantly improved at 24 weeks, but there was no significant change in the HOMA-IR. HIV-infected patients were randomized to continue their PI regimen of lopinavir/ritonavir or switch to atazanavir/ritonavir. After 6 months, the atazanavir/ritonavir group had significantly lower fasting glucose, total cholesterol, non-HDL cholesterol, triglycerides, and visceral adipose tissue (VAT) compared to those who remained on lopinavir/ritonavir. In addition, there was a significant increase in glucose uptake in the anterior thigh muscle reported in the atazanavir/ritonavir group when compared with the lopinavir/ritonavir group (79). Despite concomitant low-dose ritonavir boosting, atazanavir may have more favorable effects on glucose homeostasis compared with other PIs.

Effects on body composition $>$ In a study by Vrouenraets et al. (66), body composition assessment by CT showed that total adipose tisue (TAT) and SAT were significantly higher at 48 weeks in the atazanavir/ritonavir compared with the saquinavir/ritonavir group, and VAT tended to be higher as well in the atazanavir/ritonavir group. Haerter et al. (80) reported three case reports of HIV-infected patients switched to atazanavir from a previous PI who subjectively noted regression of abdominal and dorsoclavicular fat accumulation; however, more objective measures were needed to evaluate body composition. Regimens of atazanavir or ritonavir-boosted atazanavir in combination with an NRTI backbone of stavudine and lamivudine in treatment-naïve HIV-infected patients caused a significant increase in VAT and trunk fat at 96 weeks, but there was no statistical difference between groups. SAT also tended to increase in both groups from baseline. There was a statistically significant reduction in limb fat in the unboosted atazanavir group, while there was a trend toward reduction in limb fat in the ritonavir-boosted group (81). Body composition was also evaluated in ART-naïve patients treated with atazanavir or efavirenz in combination with zidovudine and lamivudine. Absolute VAT, SAT, and TAT tended to increase more in the atazanavir group at 48 weeks but was not significantly different from the efavirenz group (82). A significant increase was seen in the proportion of patients whose total fat changed by $\geq 20 \%$ at 12 months in HIV-infected patients who were switched from lopinavir/ ritonavir to atazanavir/ritonavir compared with those continued on their current regimen. Those in the atazanavir/ritonavir group had a statistically significant increase in trunk fat, and an increase in trunk fat $\geq 20 \%$ was associated with an increased waist-to-hip ratio in this group, but not lipid parameters (54). In the REaL study, HIV-infected patients with known abdominal adiposity were continued on their current regimen, which included a ritonavirboosted PI or switched to ritonavir-boosted atazanavir. While there was a significant increase in total fat in the atazanavir group and decrease in total fat in the other PI group at 48 weeks, this difference did not persist at 96 weeks, and in addition, there were no significant differences in VAT or SAT composition or in glucose homeostasis parameters (83). In contrast, Stanley et al. demonstrated a reduction in VAT among patients switching to atazanavir/ritonavir from lopinavir/ritonavir (79). The effects of switching to an atazanavir-based regimen on indices of body composition is not clear.

Darunavir $\vee$ Darunavir similarly inhibits the viral GagPol polyproteins in the HIV-1-infected cells, which prevent formation of mature virions (Fig. 2).

Effects on lipid parameters $>$ Total cholesterol, HDL, and triglycerides in HIV-infected treatment-naïve patients initiated on ritonavir-boosted atazanavir or darunavir in combination with tenofovir/emtricitabine were increased but were not significantly different between the atazanavir or darunavir groups at 24 weeks in the ATADAR study. The total cholesterol:HDL ratio tended to decrease more in the atazanavir group compared with the darunavir group (84). The ARTEMIS trial evaluated ART-naïve HIV-infected patients with non-suppressed viral load who were randomized to receive ritonavir-boosted darunavir or lopinavir with tenofovir/emtricitabine. At 48 weeks, increases in total cholesterol and triglycerides were higher in the lopinavir group vs the darunavir group. Although the darunavir group was receiving ritonavir at a higher dose, changes in LDL and HDL were similar in both groups (85). At 96 weeks, the triglycerides, total cholesterol, and HDL increased significantly less in the darunavir vs lopinavir group. Median total cholesterol, LDL, and triglycerides remained below NCEP guidelines in the darunavir group, but the median triglyceride level in the lopinavir group remained above NCEP guidelines (86). There were a higher percentage of patients that achieved viral suppression in the darunavir group, but there was no difference in the proportion of patients on lipid-lowering medications (87). Similar results were obtained at 196 weeks; the darunavir-treated group demonstrated a small increase in total cholesterol and triglycerides compared with the lopinavir-treated group, while there were no significant differences in LDL and HDL between groups. There were no changes from baseline in the waistto-hip ratio in either the darunavir or the lopinavir group 
and very mild changes in glucose and insulin were demonstrated at 96 weeks (86). The METABOLIK study evaluated metabolic parameters in HIV treatment-naïve patients at 48 weeks after being initiated on tenofovir/ emtricitabine with either darunavir/ritonavir or atazanavir/ritonavir. When evaluating lipid parameters, only total cholesterol and ApoA1 were significantly higher in the darunavir/ritonavir group vs the atazanavir/ritonavir group at 12 weeks, but at 48 weeks, there were no significant differences between groups (88). The POWER $1,2,3$ studies evaluated treatment-experienced patients treated with ritonavir-boosted darunavir in combination with an NRTI/NNRTI backbone, and there was a mild increase in total cholesterol, LDL, and HDL, mostly occurring in the first 12 weeks (89). Triglyceride levels tended to increase more in treatment-experienced HIV-infected patients randomized to receive lopinavir/ ritonavir vs darunavir/ritonavir with their NRTI or NNRTI backbone over 48 weeks in the TITAN study (90). In comparison to older PIs, such as lopinavir, use of darunavir may be associated with improved lipid profiles.

Effects on inflammatory indices, endothelial function, glucose homeostasis, and body composition $>$ There were no differences between groups in the METABOLIK study, which compared treatment-naïve patients initiated on a ritonavir-boosted regimen of darunavir or atazanavir in combination with tenofovir/emtricitabine, with respect to glucose homeostasis and body composition at 48 weeks. In addition, fibrinogen, D-dimer, TNF RII, and LPS decreased in both darunavir and atazanavir groups at 48 weeks, but only TNF RII was significantly lower in the darunavir/ritonavir group. There were small increases in hsCRP and IL6 in both treatment arms (88). After ART-experienced HIV-infected patients on triple ART were switched to darunavir/ritonavir monotherapy vs darunavir with two NRTIs, there was a decrease in FMD at 48 weeks, but the changes were not statistically significantly different between groups (91). Changes in VAT at 48 weeks remained stable, and there was a significant decrease in HOMA-IR in all patients. Gender differences in body composition among HIV-infected patients were investigated in the GRACE study after darunavir/ritonavir was added to medications from patients' prior regimens. At 48 weeks, glucose parameters in comparison with baseline were similar between the genders. There was a larger absolute increase in waist circumference in the women, but at 48 weeks, the waist-to-hip ratio remained similar to baseline in both genders (92). ART-experienced patients with triglyceride levels above $200 \mathrm{mg} / \mathrm{dl}$ who were on ritonavir-boosted lopinavir or fosamprenavir in addition to two NRTIs had their PI regimen switched to ritonavir-boosted darunavir. In combination with the darunavir, ritonavir was prescribed once daily compared with twice daily with the previous regimen. At 12 months, HOMA-IR decreased by $22 \%$, although not statistically significant (93). In the MONOI study, HIV-infected patients with suppressed viral loads on a stable triple drug regimen were started on darunavir/ritonavir with two NRTIs, and after 8 weeks, a subset of these patients discontinued NRTI use. Peripheral and trunk fat increased in both groups at 48 and 96 weeks, but the increase in peripheral fat was only significantly higher in the group withdrawn from NRTI use at 48 weeks (94). Changes in metabolic parameters in those exposed to darunavir may be influenced by prior ART use.

\section{Multi-class drug combinations}

Elvitegravir/cobicistat/emtricitabine/tenofovir $\bullet$ Elvitegravir/cobicistat/emtricitabine/tenofovir is a four-drug combination, which includes an integrase inhibitor, CYP3A inhibitor, and two NRTIs.

Effects on lipid parameters $\downarrow$ Total cholesterol as well as LDL at 48 weeks increased less from baseline in those treated with elvitegravir/cobicistat/emtricitabine/tenofovir when compared with those treated with efavirenz and emtricitabine/tenofovir (95), while there was no difference in the change in triglyceride levels. Previous studies have implicated efavirenz in worsening of lipid parameters (96). When combination drugs are created, adverse effects on metabolic indices could be amplified or attenuated due to the combined individual effects of each individual drug component. Elvitegravir/cobicistat/emtricitabine/ tenofovir was compared with a combination of ritonavirboosted atazanavir and emtricitabine/tenofovir. At 96 weeks, the change in cholesterol was greater in the elvitegravir/cobicistat/emtricitabine/tenofovir group, whereas there was no significant change from baseline for fasting LDL and HDL. By contrast, the change from baseline for fasting triglycerides was increased more in the ritonavir-boosted atazanavir and emtricitabine/tenofovir group (97). More studies are needed to elucidate the effect of elvitegravir/cobicistat/emtricitabine/tenofovir on lipid homeostasis.

Efavirenz/emtricitabine/tenofovir $\bullet$ Efavirenz/emtricitabine/tenofovir disoproxil fumarate is a three-drug combination consisting of two NRTIs and one NNRTI. 
Effects on lipid parameters $~-$ When ART-naïve HIVinfected patients were started on tenofovir/emtricitabine and either efavirenz or atazanavir/ritonavir, the efavirenz group demonstrated greater increases in total cholesterol and LDL, which did not differ significantly from the other regimen. In addition, there was also an increase in HDL and large HDL particles, which may have a protective effect, in the efavirenz group (98). More studies are warranted to investigate the effect of efavirenz/emtricitabine/ tenofovir on lipid homeostasis.

Effects on inflammatory indices and mitochondrial function - Inflammatory markers were evaluated at 24 and 96 weeks in treatment-naïve groups receiving either abacavir/lamivudine or tenofovir/emtricitabine with either efavirenz or atazanavir/ritonavir. At both time points, there was a reduction, but no significant difference between regimens in TNF $\alpha$, sVCAM-1, and sICAM-1 levels. HsCRP levels increased more significantly in the abacavir/lamivudine group vs the tenofovir/emtricitabine group and in the efavirenz group vs the atazanavir/ritonavir group. At 24 weeks, there was a significant decrease in IL6 levels in the tenofovir/emtricitabine group, but this decrease was similar in both groups at 96 weeks, and IL6 levels did not differ between the efavirenz or atazanavir/ ritonavir group (99). In the Advanz-3 trial, ART-naïve patients received tenofovir and emtricitabine in combination with either efavirenz or a ritonavir-boosted PI regimen. At 48 weeks, despite similar baseline characteristics, there were significant reductions in $\mathrm{sCD} 14, \mathrm{TNF} \alpha$, IL6, hsCRP, and D-dimer levels, but no difference between regimens, except for a trend towards reduced sCD14 levels in the ritonavir-boosted PI regimen (100). The effect of this combination ART strategy on inflammation should be investigated, as such studies may yield different results from assessing the individual components of therapy.

Mitochondrial function was further investigated from subcutaneous fat biopsies at baseline and 96 weeks from ART-naïve HIV-infected patients who received either abacavir/lamivudine or tenofovir/emtricitabine with either efavirenz or atazanavir/ritonavir. The abacavir/ lamivudine and tenofovir/emtricitabine groups had similar decreases in mitochondrial DNA content in the fat, but when compared with the abacavir/lamivudine group, the tenofovir/emtricitabine group had a significant decrease in the mitochondrial oxidative phosphorylation $\mathrm{NADH}$ dehydrogenase activity. There were no significant differences in mitochondrial content or function in the efavirenz vs atazanavir/ritonavir groups, but a significant reduction was seen within each group (101). Efavirenz alone has been associated with mitochondrial toxicity and oxidative stress. Previous in vitro studies report that human hepatic cells exposed to efavirenz demonstrate mitochondrial dysfunction, including altered mitochondrial morphology, ultrastructure, and mass and autophagic stress (102). In addition, genes associated with metabolic and oxidative stress are upregulated in human hepatic cells exposed to efavirenz (103). Various combinations of the components in efavirenz/emtricitabine/tenofovir may contribute to mitochondrial toxicity.

Effects on body composition - Components of this ART combination were investigated together in a study that blinded patients to receive either abacavir/lamivudine or tenofovir/emtricitabine with either efavirenz or atazanavir/ritonavir. While there was no significant difference in the groups receiving abacavir/lamivudine or tenofovir/ emtricitabine, the combination with efavirenz resulted in less weight gain and lower BMI than in combination with atazanavir/ritonavir, and multivariate analyses showed that lower CD4 count was associated with increased weight gain and BMI (104). In comparison with a treatment regimen consisting of zidovudine/lamivudine and efavirenz, patients treated with emtricitabine/tenofovir and efavirenz have significantly greater increases in limb fat at 96 weeks (105). Studies detailing body composition with efavirenz/emtricitabine/tenofovir use are limited.

\section{Rilpivirine/emtricitabine/tenofovir - Rilpivirine/} emtricitabine/tenofovir disoproxil fumarate is a three-drug combination composed of two NRTIs and one NNRTI.

Effects on lipid parameters $~-$ The SPIRIT study revealed that treatment-experienced patients started on rilpivirine/emtricitabine/tenofovir had greatly improved total cholesterol, LDL, and triglyceride levels when compared with another group on a ritonavir-boosted PI based regimen. Those on the combination therapy of rilpivirine/emtricitabine/tenofovir also had a greater improvement in Framingham cardiac risk scores at 24 weeks when compared with the ritonavirboosted PI group (106). The ECHO trial treated ART-naïve patients with emtricitabine/tenofovir with either rilpivirine or efavirenz. Patients on rilpivirine had no change in LDL or triglyceride levels, while these levels were increased on efavirenz. In addition, the rilpivirine group demonstrated a smaller increase in total cholesterol and HDL than the efavirenz group at 48 weeks (107). Similar results were reported in the THRIVE trial in which the addition of rilpivirine was again compared with efavirenz sharing a common NRTI backbone in treatment-naïve patients, and 
there was a lower increase in total cholesterol, LDL, HDL, and triglycerides at 48 weeks in the rilpivirine group vs the efavirenz group (108). Data from both the ECHO and THRIVE trial at 96 weeks demonstrates worse lipid parameters, including total cholesterol, LDL, and triglycerides, in the efavirenz group compared with the rilpivirine group, while the improvement in HDL was greater in the efavirenz group $(109,110)$. Rilpivirine may have less severe consequences on lipid parameters compared with other ART.

Effects on body composition $>$ With regard to body composition, limb fat measured by DEXA demonstrated no change regardless of treatment with rilpivirine vs efavirenz in ART-naïve patients (111). Diaz-Delfin et al. investigated the effect of rilpivirine in vitro on adipose tissue compared with efavirenz. At increased concentrations, rilpivirine reduced adipocyte differentiation, decreased expression of transcription factors involved in adipogenesis, PPAR $\gamma$, $\mathrm{C} / \mathrm{EBP} \alpha$ and SREBP-1, increased expression of proinflammatory markers MCP-1 and IL6, decreased release of adiponectin from adipocytes, and reduced mitochondrial activity measured by cytochrome II and cytochrome $c$ oxidase activity. Similar trends were seen with adipocyte exposure to efavirenz, and furthermore, effects on adipose tissue transcription factors were elicited at lower relative concentrations of efavirenz compared with rilpivirine (112). While rilpivirine appears to have many unfavorable effects in adipose tissue, the effect of this agent on body composition and related metabolic indices will need to be evaluated in HIV-infected patients.

\section{Considerations in choosing ART regimens}

ART regimens should be individualized to the patient. Previous data have demonstrated metabolic consequences of older ART, and although newer ART drugs are not free of metabolic abnormalities, data presented in this review suggest relatively more favorable profiles of newer individual ART. However, whether these favorable effects are directly related to initiation of the drug itself or withdrawal of a previously used drug remains unclear. In addition, long-term effects of these newer ART are still not determined. When choosing a regimen, priority should be given to achieving viral suppression. Indeed, viral suppression will not only decrease HIV-associated morbidity and reduce transmission rates but may also decrease immune activation, a factor known to contribute to metabolic derangement. Maraviroc serves as an interesting paradigm in the potential for the treatment of both virologic failure and attenuation of cardiovascular and inflammatory risks. Raltegravir may have more favorable effects on lipid parameters. The second-generation PIs even with ritonavir boosting also seem to have more favorable metabolic profiles, and patients may avoid more severe changes in lipid and glucose homeostasis when taking these newer agents compared with older generation PIs or higher doses of ritonavir. While multi-drug class combinations are convenient for patient adherence, the inclusion of older drugs, such as efavirenz, may adversely contribute to mitochondrial dysfunction.

\section{Future directions}

The newer classes of ART are still in the early phase of treatment, and studies determining the effects on metabolic indices and body composition are limited. Data to date suggest fewer metabolic consequences of newer ART compared with older regimens. Nonetheless, a number of important potential metabolic complications have been identified early in the development of these agents, which should increase awareness (Supplementary Table 1, see section on supplementary data given at the end of this article) and merit further long-term studies. In addition, further studies are also required to delineate the specific effects of HIV and ART in the development of cardiovascular risks. As work progresses toward a cure or vaccine to prevent HIV, novel ART are actively being developed, which may be able to control viral suppression and simultaneously inhibit critical inflammatory and atherogenic pathways. Taken together, the positive effects of ART on viral suppression far outweigh negative effects on metabolic indices, but future studies should focus on the development of even more potent novel strategies with optimal immunomodulatory and metabolic profiles.

\section{Supplementary data}

This is linked to the online version of the paper at http://dx.doi.org/10.1530/ EJE-13-0967.

\section{Declaration of interest}

Dr Grinspoon has received research funding from Bristol-Myers Squibb and EMD Serono and served as a consultant for Navidea Inc., Aileron, Inc., and BMS/AstraZeneca unrelated to this manuscript.

\section{Funding}

This review did not receive any specific grant from any funding agency in the public, commercial, or not-for-profit sector. 
Author contribution statement

S Srinivasa and S K Grinspoon contributed equally to writing and critically reviewing this manuscript, and both approved the submitted version of the manuscript.

\section{References}

1 Brown TT, Cole SR, Li X, Kingsley LA, Palella FJ, Riddler SA, Visscher BR, Margolick JB \& Dobs AS. Antiretroviral therapy and the prevalence and incidence of diabetes mellitus in the multicenter AIDS cohort study. Archives of Internal Medicine 2005165 1179-1184. (doi:10.1001/archinte.165.10.1179)

2 Brown TT, Li X, Cole SR, Kingsley LA, Palella FJ, Riddler SA, Chmiel JS, Visscher BR, Margolick JB \& Dobs AS. Cumulative exposure to nucleoside analogue reverse transcriptase inhibitors is associated with insulin resistance markers in the Multicenter AIDS Cohort Study. AIDS 200519 1375-1383. (doi:10.1097/01.aids.0000181011.62385.91)

3 Walli R, Herfort O, Michl GM, Demant T, Jager H, Dieterle C, Bogner JR, Landgraf R \& Goebel FD. Treatment with protease inhibitors associated with peripheral insulin resistance and impaired oral glucose tolerance in HIV-1-infected patients. AIDS 199812 F167-F173. (doi:10.1097/00002030-199815000-00001)

4 Mallon PW, Miller J, Cooper DA \& Carr A. Prospective evaluation of the effects of antiretroviral therapy on body composition in HIV-1-infected men starting therapy. AIDS 200317 971-979. (doi:10.1097/00002030-200305020-00005)

5 Friis-Moller N, Reiss P, Sabin CA, Weber R, Monforte A, El-Sadr W, Thiebaut R, De Wit S, Kirk O, Fontas E et al. Class of antiretroviral drugs and the risk of myocardial infarction. New England Journal of Medicine 2007356 1723-1735. (doi:10.1056/NEJMoa062744)

6 Hadigan C, Meigs JB, Corcoran C, Rietschel P, Piecuch S, Basgoz N, Davis B, Sax P, Stanley T, Wilson PW et al. Metabolic abnormalities and cardiovascular disease risk factors in adults with human immunodeficiency virus infection and lipodystrophy. Clinical Infectious Diseases 200132 130-139. (doi:10.1086/317541)

7 Riddler SA, Smit E, Cole SR, Li R, Chmiel JS, Dobs A, Palella F, Visscher B, Evans R \& Kingsley LA. Impact of HIV infection and HAART on serum lipids in men. Journal of the American Medical Association 2003289 2978-2982. (doi:10.1001/jama.289.22.2978)

8 Worm SW, Sabin C, Weber R, Reiss P, El-Sadr W, Dabis F, De Wit S, Law M, Monforte AD, Friis-Moller N et al. Risk of myocardial infarction in patients with HIV infection exposed to specific individual antiretroviral drugs from the 3 major drug classes: the data collection on adverse events of anti-HIV drugs (D:A:D) study. Journal of Infectious Diseases 2010201 318-330. (doi:10.1086/649897)

9 Triant VA, Lee H, Hadigan C \& Grinspoon SK. Increased acute myocardial infarction rates and cardiovascular risk factors among patients with human immunodeficiency virus disease. Journal of Clinical Endocrinology and Metabolism 200792 2506-2512. (doi:10.1210/jc.2006-2190)

10 Cote HC. Mechanisms of antiretroviral therapy-induced mitochondrial dysfunction. Current Opinion in HIV and AIDS 20072 253-260. (doi:10.1097/COH.0b0REF9=10.1210/jc.2006-2190)

11 Fleischman A, Johnsen S, Systrom DM, Hrovat M, Farrar CT, Frontera W, Fitch K, Thomas BJ, Torriani M, Cote HC et al. Effects of a nucleoside reverse transcriptase inhibitor, stavudine, on glucose disposal and mitochondrial function in muscle of healthy adults. American Journal of Physiology. Endocrinology and Metabolism 2007 292 E1666-E1673. (doi:10.1152/ajpendo.00550.2006)

12 Lenhard JM, Furfine ES, Jain RG, Ittoop O, Orband-Miller LA, Blanchard SG, Paulik MA \& Weiel JE. HIV protease inhibitors block adipogenesis and increase lipolysis in vitro. Antiviral Research 2000 47 121-129. (doi:10.1016/S0166-3542(00)00102-9)
13 Dowell P, Flexner C, Kwiterovich PO \& Lane MD. Suppression of preadipocyte differentiation and promotion of adipocyte death by HIV protease inhibitors. Journal of Biological Chemistry 2000275 41325-41332. (doi:10.1074/jbc.M006474200)

14 Caron M, Auclair M, Vigouroux C, Glorian M, Forest C \& Capeau J. The HIV protease inhibitor indinavir impairs sterol regulatory element-binding protein-1 intranuclear localization, inhibits preadipocyte differentiation, and induces insulin resistance. Diabetes 2001 50 1378-1388. (doi:10.2337/diabetes.50.6.1378)

15 Murata H, Hruz PW \& Mueckler M. The mechanism of insulin resistance caused by HIV protease inhibitor therapy. Journal of Biological Chemistry 2000275 20251-20254. (doi:10.1074/jbc. C000228200)

16 Riddle TM, Kuhel DG, Woollett LA, Fichtenbaum CJ \& Hui DY. HIV protease inhibitor induces fatty acid and sterol biosynthesis in liver and adipose tissues due to the accumulation of activated sterol regulatory element-binding proteins in the nucleus. Journal of Biological Chemistry 2001276 37514-37519. (doi:10.1074/jbc. M104557200)

17 den Boer MA, Berbee JF, Reiss P, van der Valk M, Voshol PJ, Kuipers F, Havekes LM, Rensen PC \& Romijn JA. Ritonavir impairs lipoprotein lipase-mediated lipolysis and decreases uptake of fatty acids in adipose tissue. Arteriosclerosis, Thrombosis, and Vascular Biology 200626 124-129. (doi:10.1161/01.ATV.0000194073.87647.10)

18 Krishnan S, Schouten JT, Atkinson B, Brown T, Wohl D, McComsey GA, Glesby MJ, Shikuma C, Haubrich R, Tebas P et al. Metabolic syndrome before and after initiation of antiretroviral therapy in treatment-naive HIV-infected individuals. Journal of Acquired Immune Deficiency Syndromes 201261 381-389. (doi:10.1097/ QAI.0b013e3182690e3c)

19 Phillips AN, Carr A, Neuhaus J, Visnegarwala F, Prineas R, Burman WJ, Williams I, Drummond F, Duprez D, Belloso WH et al. Interruption of antiretroviral therapy and risk of cardiovascular disease in persons with HIV-1 infection: exploratory analyses from the SMART trial. Antiviral Therapy 200813 177-187.

20 Fitch K, Srinivasa S, Abbara S, Burdo TH, Williams KC, Eneh P, Lo J \& Grinspoon S. Noncalcified coronary atherosclerotic plaque and immune activation in HIV-infected women. Journal of Infectious Diseases 2013208 1737-1746. (doi:10.1093/infdis/jit508)

21 Aukrust P, Halvorsen B, Yndestad A, Ueland T, Oie E, Otterdal K, Gullestad L \& Damas JK. Chemokines and cardiovascular risk. Arteriosclerosis, Thrombosis, and Vascular Biology 200828 1909-1919. (doi:10.1161/ATVBAHA.107.161240)

22 Szalai C, Duba J, Prohaszka Z, Kalina A, Szabo T, Nagy B, Horvath L \& Csaszar A. Involvement of polymorphisms in the chemokine system in the susceptibility for coronary artery disease (CAD). Coincidence of elevated Lp(a) and MCP-1 - 2518 G/G genotype in CAD patients. Atherosclerosis 2001158 233-239. (doi:10.1016/S00219150(01)00423-3)

23 Afzal AR, Kiechl S, Daryani YP, Weerasinghe A, Zhang Y, Reindl M, Mayr A, Weger S, Xu Q \& Willeit J. Common CCR5-del32 frameshift mutation associated with serum levels of inflammatory markers and cardiovascular disease risk in the Bruneck population. Stroke 200839 1972-1978. (doi:10.1161/STROKEAHA.107.504381)

24 Cipriani S, Francisci D, Mencarelli A, Renga B, Schiaroli E, D'Amore C, Baldelli F \& Fiorucci S. Efficacy of the CCR5 antagonist maraviroc in reducing early, ritonavir-induced atherogenesis and advanced plaque progression in mice. Circulation 2013127 2114-2124. (doi:10.1161/ CIRCULATIONAHA.113.001278)

25 Kelly K, Queen S, Adams R \& Mankowski J. Maraviroc prevents SIV-induced cardiac dysfunction. 19th Conference on Retroviruses and Opportunistic Infections, Seattle, March 5-8, 2012, Abstract 816.

26 Portsmouth S BR, Lazzarin A, Johnson M \& Valdez H. Incidence of ischemic cardiovascular events in the maraviroc clinical development program. 10th International Congress on Drug Therapy in HIV Infection, Glasgow, UK. 7-11 November 2010. 2010. 
27 MacInnes A, Lazzarin A, Di Perri G, Sierra-Madero JG, Aberg J, Heera J, Rajicic N, Goodrich J, Mayer H \& Valdez H. Maraviroc can improve lipid profiles in dyslipidemic patients with HIV: results from the MERIT trial. HIV Clinical Trials 2011 12 24-36. (doi:10.1310/hct1201-24)

28 Funderburg N, Kalinowska M, Eason J, Goodrich J, Heera J, Mayer H, Rajicic N, Valdez H \& Lederman MM. Effects of maraviroc and efavirenz on markers of immune activation and inflammation and associations with CD4 + cell rises in HIV-infected patients. PLOS ONE 20105 e13188. (doi:10.1371/journal.pone.0013188)

29 Hsue P SR, Gilman L, Wu Y, Maka K, Mohammed S, Grunfeld C, Martin J, Deeks S \& Hunt P. Effect of maraviroc intensification on endothelial function in treated HIV infection. 19th Conference on Retroviruses and Opportunistic Infections, Seattle, March 5-8, 2012. Abstract 123.

30 Bigoloni A, Gianotti N, Spagnuolo V, Galli L, Nozza S, Cossarini F, Salpietro S, Carini E, Piatti P, Vinci C et al. Long-term glucose tolerance in highly experienced HIV-infected patients receiving nucleoside analogue-sparing regimens. AIDS 201226 1837-1840. (doi:10.1097/ QAD.0b013e32835705dd)

31 Murray JM, Emery S, Kelleher AD, Law M, Chen J, Hazuda DJ, Nguyen BY, Teppler H \& Cooper DA. Antiretroviral therapy with the integrase inhibitor raltegravir alters decay kinetics of HIV, significantly reducing the second phase. AIDS 200721 2315-2321. (doi:10.1097/QAD.0b013e3282f12377)

32 Llibre JM, Buzon MJ, Massanella M, Esteve A, Dahl V, Puertas MC, Domingo P, Gatell JM, Larrouse M, Gutierrez M et al. Treatment intensification with raltegravir in subjects with sustained HIV-1 viraemia suppression: a randomized 48-week study. Antiviral Therapy 201217 355-364. (doi:10.3851/IMP1917)

33 Gandhi RT, Zheng L, Bosch RJ, Chan ES, Margolis DM, Read S, Kallungal B, Palmer S, Medvik K, Lederman MM et al. The effect of raltegravir intensification on low-level residual viremia in HIVinfected patients on antiretroviral therapy: a randomized controlled trial. PLoS Medicine 2010 7. (doi:10.1371/journal.pmed.1000321)

34 Huesgen E, Burgos R, Goldstein DA, Max B \& Jarrett OD. Severe dyslipidaemia after the addition of raltegravir to a lopinavir/ritonavircontaining regimen. Antiviral Therapy 201217 1385-1388. (doi:10. 3851/IMP2182)

35 Martinez E, Larrousse M, Llibre JM, Gutierrez F, Saumoy M, Antela A, Knobel H, Murillas J, Berenguer J, Pich J et al. Substitution of raltegravir for ritonavir-boosted protease inhibitors in HIV-infected patients: the SPIRAL study. AIDS 201024 1697-1707. (doi:10.1097/ QAD.0b013e32833a608a)

36 Saumoy M, Sanchez-Quesada JL, Martinez E, Llibre JM, Ribera E, Knobel H, Gatell JM, Clotet B, Curran A, Curto J et al. LDL subclasses and lipoprotein-phospholipase $\mathrm{A} 2$ activity in suppressed HIV-infected patients switching to raltegravir: Spiral substudy. Atherosclerosis 2012 225 200-207. (doi:10.1016/j.atherosclerosis.2012.REF40=10.1097/ QAI.0b013e3181da1287)

37 Boyd MA, Kumarasamy N, Moore CL, Nwizu C, Losso MH, Mohapi L, Martin A, Kerr S, Sohn AH, Teppler H et al. Ritonavir-boosted lopinavir plus nucleoside or nucleotide reverse transcriptase inhibitors versus ritonavir-boosted lopinavir plus raltegravir for treatment of HIV-1 infection in adults with virological failure of a standard first-line ART regimen (SECOND-LINE): a randomised, open-label, non-inferiority study. Lancet 2013381 2091-2099. (doi:10.1016/S01406736(13)61164-2)

38 Eron JJ, Young B, Cooper DA, Youle M, Dejesus E, AndradeVillanueva J, Workman C, Zajdenverg R, Fatkenheuer G, Berger DS et al. Switch to a raltegravir-based regimen versus continuation of a lopinavir-ritonavir-based regimen in stable HIV-infected patients with suppressed viraemia (SWITCHMRK 1 and 2): two multicentre, double-blind, randomised controlled trials. Lancet 2010375 396-407. (doi:10.1016/S0140-6736(09)62041-9)

39 Lennox JL, DeJesus E, Lazzarin A, Pollard RB, Madruga JV, Berger DS, Zhao J, Xu X, Williams-Diaz A, Rodgers AJ et al. Safety and efficacy of raltegravir-based versus efavirenz-based combination therapy in treatment-naive patients with HIV-1 infection: a multicentre, double-blind randomised controlled trial. Lancet 2009374 796-806. (doi:10.1016/S0140-6736(09)60918-1)

40 Lennox JL, Dejesus E, Berger DS, Lazzarin A, Pollard RB, Ramalho Madruga JV, Zhao J, Wan H, Gilbert CL, Teppler H et al. Raltegravir versus Efavirenz regimens in treatment-naive HIV-1-infected patients: 96-week efficacy, durability, subgroup, safety, and metabolic analyses. Journal of Acquired Immune Deficiency Syndromes 201055 39-48. (doi:10.1097/QAI.0b013e3181da1287)

41 Rockstroh JK, Lennox JL, Dejesus E, Saag MS, Lazzarin A, Wan H, Walker ML, Xu X, Zhao J, Teppler H et al. Long-term treatment with raltegravir or efavirenz combined with tenofovir/emtricitabine for treatment-naive human immunodeficiency virus-1-infected patients: 156-week results from STARTMRK. Clinical Infectious Diseases 201153 807-816. (doi:10.1093/cid/cir510)

42 Rockstroh JK, DeJesus E, Lennox JL, Yazdanpanah Y, Saag MS, Wan H, Rodgers AJ, Walker ML, Miller M, DiNubile MJ et al. Durable efficacy and safety of raltegravir versus efavirenz when combined with tenofovir/emtricitabine in treatment-naive HIV-1-infected patients: final 5-year results from STARTMRK. Journal of Acquired Immune Deficiency Syndromes 201363 77-85. (doi:10.1097/QAI. ob013e31828ace69)

43 Eron JJ Jr, Rockstroh JK, Reynes J, Andrade-Villanueva J, RamalhoMadruga JV, Bekker LG, Young B, Katlama C, Gatell-Artigas JM, Arribas JR et al. Raltegravir once daily or twice daily in previously untreated patients with HIV-1: a randomised, active-controlled, phase 3 non-inferiority trial. Lancet Infectious Diseases 201111 907-915. (doi:10.1016/S1473-3099(11)70196-7)

44 Gotuzzo E, Markowitz M, Ratanasuwan W, Smith G, Prada G, MoralesRamirezJO, Strohmaier KM, Lu C, Bhanja S, Nguyen BY et al. Sustained efficacy and safety of raltegravir after 5 years of combination antiretroviral therapy as initial treatment of HIV-1 infection: final results of a randomized, controlled, phase II study (Protocol 004). Journal of Acquired Immune Deficiency Syndromes 201261 73-77. (doi:10.1097/QAI.0b013e318263277e)

45 Young B, Vanig T, Dejesus E, Hawkins T, St Clair M, Yau L, Ha B \& Shield Study Team . A pilot study of abacavir/lamivudine and raltegravir in antiretroviral-naive HIV-1-infected patients: 48-week results of the SHIELD trial. HIV Clinical Trials 201011 260-269. (doi:10.1310/hct1105-260)

46 Hatano H, Scherzer R, Wu Y, Harvill K, Maka K, Hoh R, Sinclair E, Palmer S, Martin JN, Busch MP et al. A randomized controlled trial assessing the effects of raltegravir intensification on endothelial function in treated HIV infection. Journal of Acquired Immune Deficiency Syndromes 201261 317-325. (doi:10.1097/QAI.0b013e31826e7d0f)

47 Masia M, Martinez E, Padilla S, Gatell JM \& Gutierrez F. Endothelial function in HIV-infected patients switching from a boosted protease inhibitor-based regimen to raltegravir: a substudy of the SPIRAL study. Journal of Antimicrobial Chemotherapy 201368 409-413. (doi:10.1093/ $\mathrm{jac} / \mathrm{dks} 412)$

48 Silva EF, Charreau I, Gourmel B, Mourah S, Kalidi I, Guillon B, De Castro N, Caron F, Braun J \& Molina JM. Decreases in inflammatory and coagulation biomarkers levels in HIV-infected patients switching from enfuvirtide to raltegravir: ANRS 138 substudy. Journal of Infectious Diseases 2013208 892-897. (doi:10.1093/infdis/jit280)

49 Martinez E, D'Albuquerque PM, Llibre JM, Gutierrez F, Podzamczer D, Antela A, Berenguer J, Domingo P, Moreno X, Perez I et al. Changes in cardiovascular biomarkers in HIV-infected patients switching from ritonavir-boosted protease inhibitors to raltegravir. AIDS $2012 \mathbf{2 6}$ 2315-2326. (doi:10.1097/QAD.0b013e328359f29c)

50 Lake J, McComsey G, Hulgan T, Wanke C, Mangili A, Walmsley S, Boger S, Stramotas D \& Currier J. Soluble CD14 declines in virologically suppressed women switching from protease inhibitor or NNRTI to raltegravir: the women, integrase, and fat accumulation trial. 20th Conference on Retroviruses and Opportunistic Infections, Atlanta, March 3-6, 2013. Abstract 794. 
51 Taiwo B, Matining RM, Zheng L, Lederman MM, Rinaldo CR, Kim PS, Berzins BI, Kuritzkes DR, Jennings A, Eron JJ Jr et al. Associations of T cell activation and inflammatory biomarkers with virological response to darunavir/ritonavir plus raltegravir therapy. Journal of Antimicrobial Chemotherapy 201368 1857-1861. (doi:10.1093/jac/dkt120)

52 Pallikkuth S, Fischl MA \& Pahwa S. Combination antiretroviral therapy with raltegravir leads to rapid immunologic reconstitution in treatment-naive patients with chronic HIV infection. Journal of Infectious Diseases 2013208 1613-1623. (doi:10.1093/infdis/jit387)

53 Ceccarelli G, d'Ettorre G, Marchetti F, Rizza C, Mastroianni CM, Carlesimo B \& Vullo V. Development of Buffalo Hump in the course of antiretroviral therapy including raltegravir and unboosted atazanavir: a case report and review of the literature. Journal of Medical Case Reports 20115 70. (doi:10.1186/1752-1947-5-70)

54 Ferrer E, del Rio L, Martinez E, Curto J, Domingo P, Ribera E, Negredo E, Rosales J, Saumoy M, Ordonez J et al. Impact of switching from lopinavir/ritonavir to atazanavir/ritonavir on body fat redistribution in virologically suppressed HIV-infected adults. AIDS Research and Human Retroviruses 201127 1061-1065. (doi:10.1089/aid. 2010.0254)

55 Lake JE, McComsey GA, Hulgan TM, Wanke CA, Mangili A, Walmsley SL, Boger MS, Turner RR, McCreath HE \& Currier JS. A randomized trial of Raltegravir replacement for protease inhibitor or non-nucleoside reverse transcriptase inhibitor in HIV-infected women with lipohypertrophy. AIDS Patient Care and STDS 201226 532-540. (doi:10.1089/apc.2012.0135)

56 Murphy RL, Berzins B, Zala C, Fichtenbaum C, Dube MP, Guaraldi G, Torriani F, Belsey E, Mitchell C \& Stein JH. Change to atazanavir/ritonavir treatment improves lipids but not endothelial function in patients on stable antiretroviral therapy. AIDS 201024 885-890. (doi:10.1097/QAD.0b013e3283352ed5)

57 Cohen C, Nieto-Cisneros L, Zala C, Fessel WJ, Gonzalez-Garcia J, Gladysz A, McGovern R, Adler E \& McLaren C. Comparison of atazanavir with lopinavir/ritonavir in patients with prior protease inhibitor failure: a randomized multinational trial. Current Medical Research and Opinion 200521 1683-1692. (doi:10.1185/ 030079905X65439)

58 Calza L, Manfredi R, Colangeli V, Pocaterra D, Rosseti N, Pavoni M \& Chiodo F. Efficacy and safety of atazanavir-ritonavir plus abacavirlamivudine or tenofovir-emtricitabine in patients with hyperlipidaemia switched from a stable protease inhibitor-based regimen including one thymidine analogue. AIDS Patient Care and STDS 2009 23 691-697. (doi:10.1089/apc.2009.0039)

59 Mobius U, Lubach-Ruitman M, Castro-Frenzel B, Stoll M, Esser S, Voigt E, Christensen S, Rump JA, Fatkenheuer G, Behrens GM et al. Switching to atazanavir improves metabolic disorders in antiretroviral-experienced patients with severe hyperlipidemia. Journal of Acquired Immune Deficiency Syndromes 200539 174-180.

60 Sension M, Andrade Neto JL, Grinsztejn B, Molina JM, Zavala I, Gonzalez-Garcia J, Donnelly A, Phiri P, Ledesma E \& McGrath D. Improvement in lipid profiles in antiretroviral-experienced HIVpositive patients with hyperlipidemia after a switch to unboosted atazanavir. Journal of Acquired Immune Deficiency Syndromes $2009 \mathbf{5 1}$ 153-162. (doi:10.1097/QAI.0b013e3181a5701c)

61 Mallolas J, Podzamczer D, Milinkovic A, Domingo P, Clotet B, Ribera E, Gutierrez F, Knobel H, Cosin J, Ferrer E et al. Efficacy and safety of switching from boosted lopinavir to boosted atazanavir in patients with virological suppression receiving a LPV/r-containing HAART: the ATAZIP study. Journal of Acquired Immune Deficiency Syndromes 200951 29-36. (doi:10.1097/QAI.0b013e31819a226f)

62 Gatell J, Salmon-Ceron D, Lazzarin A, Van Wijngaerden E, Antunes F, Leen C, Horban A, Wirtz V, Odeshoo L, Van den Dungen M et al. Efficacy and safety of atazanavir-based highly active antiretroviral therapy in patients with virologic suppression switched from a stable, boosted or unboosted protease inhibitor treatment regimen: the
SWAN Study (AI424-097) 48-week results. Clinical Infectious Diseases 200744 1484-1492. (doi:10.1086/517497)

63 van Vonderen MG, Gras L, Wit F, Brinkman K, van der Ende ME, Hoepelman AI, de Wolf F \& Reiss P. Baseline lipid levels rather than the presence of reported body shape changes determine the degree of improvement in lipid levels after switching to atazanavir. HIV Clinical Trials 200910 168-180. (doi:10.1310/hct1003-168)

64 Monforte A, Reiss P, Ryom L, El-Sadr W, Dabis F, De Wit S, Worm SW, Law MG, Weber R, Kirk O et al. Atazanavir is not associated with an increased risk of cardio- or cerebrovascular disease events. AIDS 2013 27 407-415. (doi:10.1097/QAD.0b013e32835b2ef1)

65 Kumar PN, Salvato P, Lamarca A, Dejesus E, Patel P, McClernon D, Florance A \& Shaefer MS. A randomized, controlled trial of initial antiretroviral therapy with abacavir/lamivudine/zidovudine twice-daily compared to atazanavir once-daily with lamivudine/zidovudine twice-daily in HIV-infected patients over 48 weeks (ESS100327, the ACTION Study). AIDS Research and Therapy 20096 3. (doi:10.1186/ 1742-6405-6-3)

66 Vrouenraets SM, Wit FW, Fernandez Garcia E, Moyle GJ, Jackson AG, Allavena C, Raffi F, Jayaweera DT, Mauss S, Katlama C et al. Randomized comparison of metabolic and renal effects of saquinavir/r or atazanavir/r plus tenofovir/emtricitabine in treatment-naive HIV-1infected patients. HIV Medicine 201112 620-631. (doi:10.1111/j.14681293.2011.00941.x)

67 Gyalrong-Steur M, Bogner JR \& Seybold U. Changes in lipid profiles after switching to a protease inhibitor-containing cART - unfavourable effect of fosamprenavir in obese patients. European Journal of Medical Research 201116 85-92. (doi:10.1186/2047-783X-16-2-85)

68 Molina JM, Andrade-Villanueva J, Echevarria J, Chetchotisakd P, Corral J, David N, Moyle G, Mancini M, Percival L, Yang R et al. Oncedaily atazanavir/ritonavir versus twice-daily lopinavir/ritonavir, each in combination with tenofovir and emtricitabine, for management of antiretroviral-naive HIV-1-infected patients: 48 week efficacy and safety results of the CASTLE study. Lancet 2008372 646-655. (doi:10. 1016/S0140-6736(08)61081-8)

69 Kozal MJ, Lupo S, Dejesus E, Molina JM, McDonald C, Raffi F, Benetucci J, Mancini M, Yang R, Wirtz V et al. A nucleoside- and ritonavir-sparing regimen containing atazanavir plus raltegravir in antiretroviral treatment-naive HIV-infected patients: SPARTAN study results. HIV Clinical Trials 201213 119-130. (doi:10.1310/ hct1303-119)

70 Podzamczer D, Andrade-Villanueva J, Clotet B, Taylor S, Rockstroh JK, Reiss P, Domingo P, Gellermann HJ, de Rossi L, Cairns V et al. Lipid profiles for nevirapine vs. atazanavir/ritonavir, both combined with tenofovir disoproxil fumarate and emtricitabine over 48 weeks, in treatment-naive HIV-1-infected patients (the ARTEN study). HIV Medicine 201112 374-382. (doi:10.1111/j.1468-1293.2011.00917.x)

71 Hileman C, Longenecker C, Carman T, Milne G, Labbato DE, Storer N, White C \& McComsey G. Relationship between total bilirubin and endothelial function, inflammation and oxidative stress in HIVinfected adults on stable antiretroviral therapy. HIV Medicine $2012 \mathbf{1 3}$ 609-616. (doi:10.1111/j.1468-1293.2012.01026.x)

72 Zhang D, Chando TJ, Everett DW, Patten CJ, Dehal SS \& Humphreys WG. In vitro inhibition of UDP glucuronosyltransferases by atazanavir and other HIV protease inhibitors and the relationship of this property to in vivo bilirubin glucuronidation. Drug Metabolism and Disposition 200533 1729-1739. (doi:10.1124/dmd.105.005447)

73 Flammer AJ, Vo NT, Ledergerber B, Hermann F, Gamperli A, Huttner A, Evison J, Baumgartner I, Cavassini M, Hayoz D et al. Effect of atazanavir versus other protease inhibitor-containing antiretroviral therapy on endothelial function in HIV-infected persons: randomised controlled trial. Heart 200995 385-390. (doi:10.1136/hrt.2007. 137646)

74 Colafigli M, Di Giambenedetto S, Bracciale L, Tamburrini E, Cauda R \& De Luca A. Cardiovascular risk score change in HIV-1-infected patients 
switched to an atazanavir-based combination antiretroviral regimen. HIV Medicine 2008 9172-179. (doi:10.1111/j.1468-1293.2007.00541.x)

75 Young B, Squires KE, Ross LL, Santiago L, Sloan LM, Zhao HH, Wine BC, Pakes GE, Margolis DA \& Shaefer MS. Inflammatory biomarker changes and their correlation with Framingham cardiovascular risk and lipid changes in antiretroviral-naive HIV-infected patients treated for 144 weeks with abacavir/lamivudine/atazanavir with or without ritonavir in ARIES. AIDS Research and Human Retroviruses 201329 350-358. (doi:10.1089/AID.2012.0278)

76 de Saint-Martin L, Bressollette L, Perfezou P, Bellein V, Ansart S, Vallet $\mathrm{S} \&$ Pasquier E. Impact of atazanavir-based HAART regimen on the carotid intima-media thickness of HIV-infected persons: a comparative prospective cohort. AIDS 201024 2797-2801. (doi:10. 1097/QAD.0b013e328340a21f)

77 Busti AJ, Bedimo R, Margolis DM \& Hardin DS. Improvement in insulin sensitivity and dyslipidemia in protease inhibitor-treated adult male patients after switch to atazanavir/ritonavir. Journal of Investigative Medicine 200856 539-544. (doi:10.231/JIM. 0b013e3181641b26)

78 Guffanti M, Caumo A, Galli L, Bigoloni A, Galli A, Dagba G, Danise A, Luzi L, Lazzarin A \& Castagna A. Switching to unboosted atazanavir improves glucose tolerance in highly pretreated HIV-1 infected subjects. European Journal of Endocrinology 2007156 503-509. (doi:10.1530/EJE-06-0648)

79 Stanley TL, Joy T, Hadigan CM, Liebau JG, Makimura H, Chen CY, Thomas BJ, Weise SB, Robbins GK \& Grinspoon SK. Effects of switching from lopinavir/ritonavir to atazanavir/ritonavir on muscle glucose uptake and visceral fat in HIV-infected patients. AIDS 200923 1349-1357. (doi:10.1097/QAD.0b013e32832ba904)

80 Haerter G, Manfras BJ, Mueller M, Kern P \& Trein A. Regression of lipodystrophy in HIV-infected patients under therapy with the new protease inhibitor atazanavir. AIDS 200418 952-955. (doi:10.1097/ 00002030-200404090-00016)

81 McComsey G, Rightmire A, Wirtz V, Yang R, Mathew M \& McGrath D. Changes in body composition with ritonavir-boosted and unboosted atazanavir treatment in combination with Lamivudine and Stavudine: a 96-week randomized, controlled study. Clinical Infectious Diseases 200948 1323-1326. (doi:10.1086/597776)

82 Jemsek JG, Arathoon E, Arlotti M, Perez C, Sosa N, Pokrovskiy V, Thiry A, Soccodato M, Noor MA \& Giordano M. Body fat and other metabolic effects of atazanavir and efavirenz, each administered in combination with zidovudine plus lamivudine, in antiretroviral-naive HIV-infected patients. Clinical Infectious Diseases 200642 273-280. (doi:10.1086/498505)

83 Moyle GJ, Andrade-Villanueva J, Girard PM, Antinori A, Salvato P, Bogner JR, Hay P, Santos J, Astier L, Pans M et al. A randomized comparative 96-week trial of boosted atazanavir versus continued boosted protease inhibitor in HIV-1 patients with abdominal adiposity. Antiviral Therapy 201217 689-700. (doi:10.3851/IMP2083)

84 Martinez E, Gonzalez-Cordon A, Ferrer E, Domingo P, Negredo E, Gutierrez F, Portilla J, Curran A, Podzamczer D, Murillas J et al. Early lipid changes with atazanavir/ritonavir or darunavir/ritonavir. HIV Medicine 2014. In press. (doi:10.1111/hiv.12121)

85 Ortiz R, Dejesus E, Khanlou H, Voronin E, van Lunzen J, AndradeVillanueva J, Fourie J, De Meyer S, De Pauw M, Lefebvre E et al. Efficacy and safety of once-daily darunavir/ritonavir versus lopinavir/ritonavir in treatment-naive HIV-1-infected patients at week 48. AIDS 200822 1389-1397. (doi:10.1097/QAD.0b013e32830285fb)

86 Arathoon E, Schneider S, Baraldi E, Lim PL, Opravil M, Van De Casteele T \& Lavreys L. Effects of once-daily darunavir/ritonavir versus lopinavir/ritonavir on metabolic parameters in treatment-naive HIV-1-infected patients at week 96: ARTEMIS. International Journal of STD \& AIDS 201324 12-17. (doi:10.1258/ijsa.2012.012120)

87 Mills AM, Nelson M, Jayaweera D, Ruxrungtham K, Cassetti I, Girard PM, Workman C, Dierynck I, Sekar V, Abeele CV et al. Oncedaily darunavir/ritonavir vs. lopinavir/ritonavir in treatment-naive,
HIV-1-infected patients: 96-week analysis. AIDS 200923 1679-1688. (doi:10.1097/QAD.0b013e32832d7350)

88 Aberg JA, Tebas P, Overton ET, Gupta SK, Sax PE, Landay A, Falcon R, Ryan R \& De La Rosa G. Metabolic effects of darunavir/ritonavir versus atazanavir/ritonavir in treatment-naive, HIV type 1-infected subjects over 48 weeks. AIDS Research and Human Retroviruses 201228 1184-1195. (doi:10.1089/aid.2011.0327)

89 Arasteh K, Yeni P, Pozniak A, Grinsztejn B, Jayaweera D, Roberts A, Hoy J, De Meyer S, Vangeneugden T \& Tomaka F. Efficacy and safety of darunavir/ritonavir in treatment-experienced HIV type-1 patients in the POWER 1, 2 and 3 trials at week 96. Antiviral Therapy $2009 \mathbf{1 4}$ 859-864. (doi:10.3851/IMP1301)

90 Madruga JV, Berger D, McMurchie M, Suter F, Banhegyi D, Ruxrungtham K, Norris D, Lefebvre E, de Bethune MP, Tomaka F et al. Efficacy and safety of darunavir-ritonavir compared with that of lopinavir-ritonavir at 48 weeks in treatment-experienced, HIVinfected patients in TITAN: a randomised controlled phase III trial. Lancet 2007370 49-58. (doi:10.1016/S0140-6736(07)61049-6)

91 Guaraldi G, Zona S, Cossarizza A, Vernacotola L, Carli F, Lattanzi A, Beghetto B, Orlando G, De Biasi S, Termini R et al. Randomized trial to evaluate cardiometabolic and endothelial function in patients with plasma HIV-1 RNA suppression switching to darunavir/ritonavir with or without nucleoside analogues. HIV Clinical Trials 201314 140-148. (doi:10.1310/hct1404-140)

92 Currier JS, Martorell C, Osiyemi O, Yin MT, Ryan R, De La Rosa G \& Mrus J. Effects of darunavir/ritonavir-based therapy on metabolic and anthropometric parameters in women and men over 48 weeks. AIDS Patient Care and STDS 201125 333-340. (doi:10.1089/apc.2010.0386)

93 Ucciferri C, Falasca K, Vignale F, Di Nicola M, Pizzigallo E \& Vecchiet J. Improved metabolic profile after switch to darunavir/ritonavir in HIV positive patients previously on protease inhibitor therapy. Journal of Medical Virology 201385 755-759. (doi:10.1002/jmv.23543)

94 Valantin MA, Kolta S, Flandre P, Algarte Genin M, Meynard JL, Ponscarme D, Slama L, Cuzin L, de Kerviler E, Inaoui R et al. Body fat distribution in HIV-infected patients treated for 96 weeks with darunavir/ritonavir monotherapy versus darunavir/ritonavir plus nucleoside reverse transcriptase inhibitors: the MONOI-ANRS136 substudy. HIV Medicine 201213 505-515. (doi:10.1111/j.1468-1293. 2012.01004.x)

95 Sax PE, DeJesus E, Mills A, Zolopa A, Cohen C, Wohl D, Gallant JE, Liu HC, Zhong L, Yale K et al. Co-formulated elvitegravir, cobicistat, emtricitabine, and tenofovir versus co-formulated efavirenz, emtricitabine, and tenofovir for initial treatment of HIV-1 infection: a randomised, double-blind, phase 3 trial, analysis of results after 48 weeks. Lancet 2012379 2439-2448. (doi:10.1016/S01406736(12)60917-9)

96 Tashima KT, Bausserman L, Alt EN, Aznar E \& Flanigan TP. Lipid changes in patients initiating efavirenz- and indinavir-based antiretroviral regimens. HIV Clinical Trials 20034 29-36. (doi:10.1310/F2V7-3R46-VX6J-241R)

97 Rockstroh JK, DeJesus E, Henry K, Molina JM, Gathe J, Ramanathan S, Wei X, Plummer A, Abram M, Cheng AK et al. A randomized, doubleblind comparison of coformulated elvitegravir/cobicistat/emtricitabine/tenofovir DF vs ritonavir-boosted atazanavir plus coformulated emtricitabine and tenofovir DF for initial treatment of HIV-1 infection: analysis of week 96 results. Journal of Acquired Immune Deficiency Syndromes 201362 483-486. (doi:10.1097/QAI. Ob013e318286415c)

98 Gotti D, Cesana BM, Albini L, Calabresi A, Izzo I, Foca E, Motta D, Bellagamba R, Fezza R, Narciso P et al. Increase in standard cholesterol and large HDL particle subclasses in antiretroviral-naive patients prescribed efavirenz compared to atazanavir/ritonavir. HIV Clinical Trials 201213 245-255. (doi:10.1310/hct1305-245)

99 McComsey GA, Kitch D, Daar ES, Tierney C, Jahed NC, Melbourne K, Ha B, Brown TT, Bloom A, Fedarko N et al. Inflammation markers after randomization to abacavir/lamivudine or tenofovir/emtricitabine 
with efavirenz or atazanavir/ritonavir. AIDS 201226 1371-1385 (doi:10.1097/QAD.0b013e328354f4fb)

100 Miro J MC, Guardo A, Lozano F, Ferrer E, Domingo P, Curran A, Clotet B, Plana M, Gatell J \& the Advanz-3 Investigators. Effect of cART on bacterial transloaction, inflammation, coagulation, and immune activation markers in advanced ARV-naive patients $(<100$ CD4+ cell/mm3). 19th Conference on Retroviruses and Opportunistic Infections, Seattle, March 5-8, 2012, Abstract 276.

101 McComsey GA, Daar ES, O'Riordan M, Collier AC, Kosmiski L, Santana JL, Fichtenbaum CJ, Fink H, Sax PE, Libutti DE et al. Changes in fat mitochondrial DNA and function in subjects randomized to abacavir-lamivudine or tenofovir DF-emtricitabine with atazanavirritonavir or efavirenz: AIDS Clinical Trials Group study A5224s, substudy of A5202. Journal of Infectious Diseases 2013207 604-611. (doi:10.1093/infdis/jis720)

102 Apostolova N, Gomez-Sucerquia LJ, Gortat A, Blas-Garcia A \& Esplugues JV. Autophagy as a rescue mechanism in efavirenz-induced mitochondrial dysfunction: a lesson from hepatic cells. Autophagy 20117 1402-1404. (doi:10.4161/auto.7.11.17653)

103 Gomez-Sucerquia LJ, Blas-Garcia A, Marti-Cabrera M, Esplugues JV \& Apostolova N. Profile of stress and toxicity gene expression in human hepatic cells treated with Efavirenz. Antiviral Research 201294 232-241. (doi:10.1016/j.antiviral.2012.04.003)

104 Erlandson K KD, Tierney C, Sax P, Daar E, Tebas P, Melbourne K, Ha B, Jahed $\mathrm{N} \&$ McComsey G. Change in lean body mass and association with bone mineral density change in subjects randomized to abacavir/lamivudine or tenofovir/emtricitabine with atazanavir/ ritonavir or efavirenz: ACTG A5224s. 20th Conference on Retroviruses and Opportunistic Infections, Atlanta, March 3-6, 2013. Abstract 825.

105 Pozniak AL, Gallant JE, DeJesus E, Arribas JR, Gazzard B, Campo RE, Chen SS, McColl D, Enejosa J, Toole JJ et al. Tenofovir disoproxil fumarate, emtricitabine, and efavirenz versus fixed-dose zidovudine/lamivudine and efavirenz in antiretroviral-naive patients: virologic, immunologic, and morphologic changes - a 96-week analysis. Journal of Acquired Immune Deficiency Syndromes 200643 535-540.

106 Palella F TP, Gazzard B, Ruane P, Shamblaw D, Flamm J, Fisher M, van Lunzen J, Ebrahimi R, White K, Guyer B, et al. SPIRIT study: switching to emtricitabine/rilpivirine/tenofovir df single-tablet regimen from a ritonavir-boosted protease inhibitor and two nucleosie reverse transcriptase inhibitors maintains HIV suppression and improves seru. 19th International AIDS Conference, July 22-27, 2012, Washington DC, Abstract TUABO104.

107 Molina JM, Cahn P, Grinsztejn B, Lazzarin A, Mills A, Saag M, Supparatpinyo K, Walmsley S, Crauwels H, Rimsky LT et al. Rilpivirine versus efavirenz with tenofovir and emtricitabine in treatment-naive adults infected with HIV-1 (ECHO): a phase 3 randomised doubleblind active-controlled trial. Lancet 2011378 238-246. (doi:10.1016/ S0140-6736(11)60936-7)

108 Cohen CJ, Andrade-Villanueva J, Clotet B, Fourie J, Johnson MA, Ruxrungtham K, Wu H, Zorrilla C, Crauwels H, Rimsky LT et al. Rilpivirine versus efavirenz with two background nucleoside or nucleotide reverse transcriptase inhibitors in treatment-naive adults infected with HIV-1 (THRIVE): a phase 3, randomised, non-inferiority trial. Lancet 2011378 229-237. (doi:10.1016/S01406736(11)60983-5)

109 Molina JM, Clumeck N, Orkin C, Rimsky L, Vanveggel S \& Stevens M. Week 96 analysis of rilpivirine or efavirenz in HIV-1-infected patients with baseline viral load $</=100000$ copies $/ \mathrm{mL}$ in the pooled ECHO and THRIVE phase 3, randomized, double-blind trials. HIV Medicine 201315 57-62. (doi:10.1111/hiv.12071)

110 Molina JM, Clumeck N, Redant K, Rimsky L, Vanveggel S \& Stevens M. Rilpivirine vs. efavirenz in HIV-1 patients with baseline viral load 100,000 copies/ml or less: week 48 phase III analysis. AIDS 201327 889-897. (doi:10.1097/QAD.0b013e32835e1554)

111 Tebas PHK, Nelson M, Reynes J, Ruxrungtham K, Sierra-Madero J, Vanveggel S, Deckx H \& Boven K. Results from the pooled DEXA substudies of the double-blind, randomised, Phase III trials comparing rilpivirine (RPV, TMC278) versus efavirenz (EFV) in treatment-naive, HIV-1-infected adults. Antiviral Therapy 201116 A19.

112 Diaz-Delfin J, Domingo P, Mateo MG, Gutierrez Mdel M, Domingo JC, Giralt M \& Villarroya F. Effects of rilpivirine on human adipocyte differentiation, gene expression, and release of adipokines and cytokines. Antimicrobial Agents and Chemotherapy 201256 3369-3375. (doi:10.1128/AAC.00104-12)

113 Smith RL, de Boer R, Brul S, Budovskaya Y \& van Spek H. Premature and accelerated aging: HIV or HAART? Frontiers in Genetics 20123328. (doi:10.3389/fgene.2012.00328)

Received 27 November 2013

Revised version received 3 February 2014

Accepted 12 February 2014 